Journal of Educational

and Psychological Sciences

Volume (5), Issue (31): 30 Aug 2021

P: 1 - 19

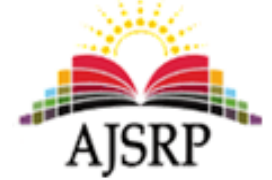

ISSN: 2522-3399

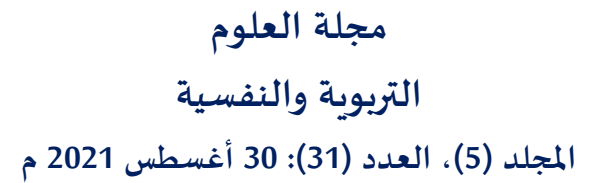

ص: 19

\title{
The Effectiveness of Blended Learning by Using Wiki in Developing on Writing Skills among male and female Basic Grade Six Students in The Sultanate of Oman
}

\section{Amal Saleem Mohammed Alshabibi}

\begin{abstract}
The study aimed to test the effectiveness of blended learning using wiki in developing written expression skills for sixth grade students. The researcher used the quasi-experimental approach. To achieve this, the researcher adopted an achievement test and a list of skills for written expression (Soliman, 2016) that was previously presented to a group of specialized referees to ensure their validity. And the test reliability is calculated by internal consistency.

The study sample was divided into two experimental groups that included 30 students who studied the description lesson in the book My Writing Skills through the application of wiki, and a control sample of 30 students studied the same lesson in the traditional way, and after completing the experiment, a written expression skills test was applied to the two groups.

The results indicated that there were statistically significant differences at the level of significance $(0.05 \geq \alpha)$ between the mean scores of the two experimental groups and obtained an overall average (34.57 out of 42), in contrast to the control receiving an overall average (30.33 out of 42 ), in a test attributed to the blended learning strategy. By using wiki, and in basic skills of written expression, where the experimental in the content skill got an average (14.7 out of 18) and the control got (12.8) and in the skill of form and organization; Empiric got average (7.77 out of 9), control (7.33), and finally language and style skill; The experimental got a mean (12.1 out of 15), while the control (10.2). The differences were statistically significant in the skills of content, language and style in favor of the experimental group, while the differences between the two groups were not significant in the skill of form and organization,

Based on these results, the researcher recommended paying attention to developing written expression skills among students by adopting blended learning using wiki and training Arabic language teachers on how to use it, in addition to expanding the use of blended learning strategy using wiki to teach other Arabic language skills such as reading and grammar.
\end{abstract}

Keywords: wiki, blended learning, written expression skills, Sultanate of Oman.

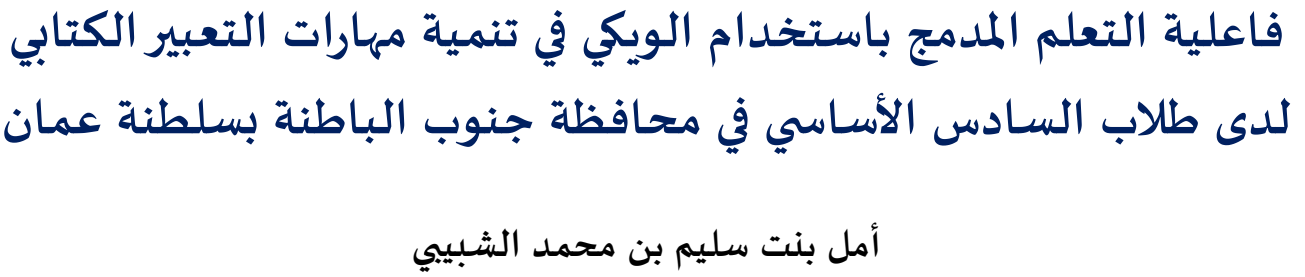

المستخلص: هدفت الدراسة إلى اختبار فاعلية التعلم المدمج باستخدام الويكي في تنمية مهارات التعبير الكتابي لدى طلاب الصف السادس الأسـاسي واستخدمت الباحثة المنهج شبه التجريبي ولتحقيق ذلك اعتمدت الباحثة اختباراً تحصيلياً وقائمة مهارات للتعبير الكتابي (سليمان، 2016) التي عرضت مسبقا على مجموعة من المحكمين المختصين للتأكد من صدافها وتم حساب ثبات الاختبار بالاتساق الداخلي. 


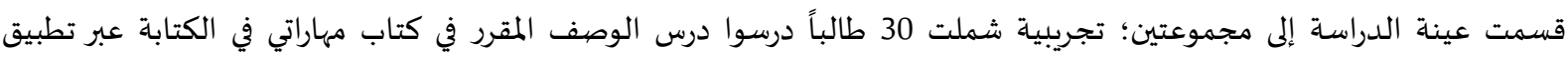

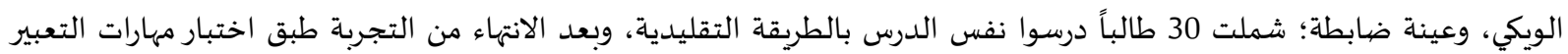

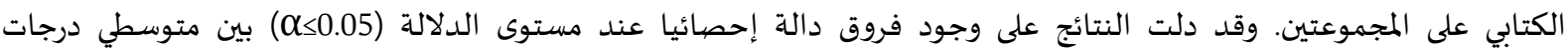

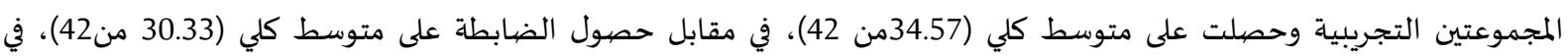

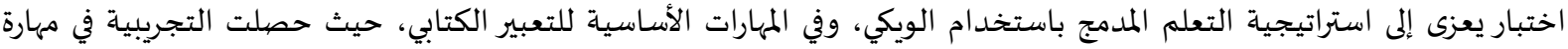

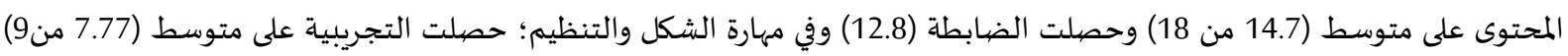

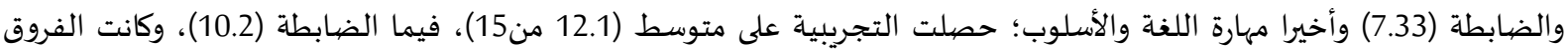

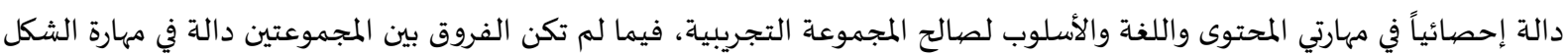
والتنظيم، وبناء على هذه النتائج فقد أوصت الباحثة بالاهتمام بتنمية مهارات التعبير الكتابي لدى الطلاب باعتماد التعلم المدمج باستخدام الويكي

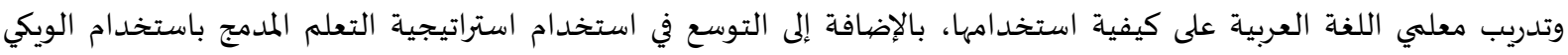
لتدريس مهارات اللغة العربية الأخرى كالقراءة والنحو. الكلمات المفتاحية: الويكي، التعلم المدمج، مهارات التعبير الكتابي، سلطنة عمان

المقدمة.

تشمل اللغة العربية أربع مهارات رئيسية: القراءة والاستماع والتحدث والكتابة، وتعد الكتابة أهم مهارة من

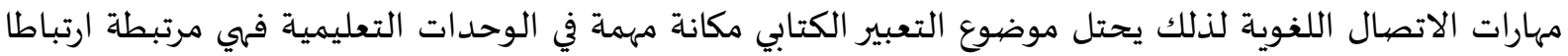

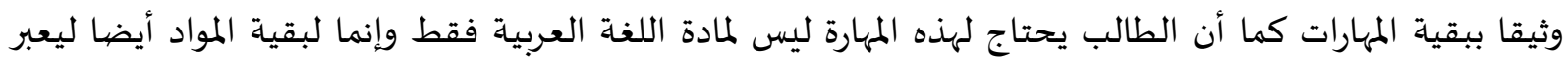
عن أفكاره بطريقة صحيحة. وينقسم التعبير من حيث الموضوع إلى نوعين: تعبير وظيفي والغرض منه تنظيم اتصال الناس بعضههم

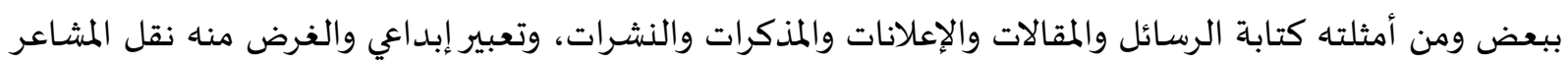

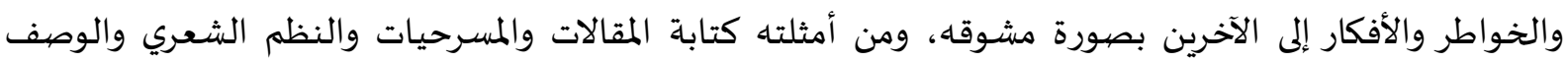
وتأليف القصص.

وينقسم التعبير من حيث الأداء إلى: تعبير شفوي وهو التعبير عن المشاعروالمواقف الاجتماعية شفاهة سواء

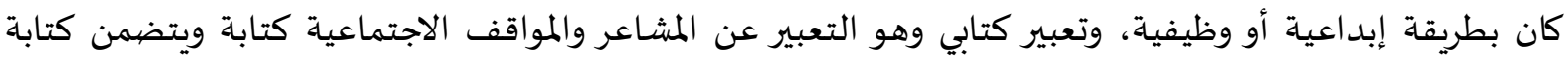

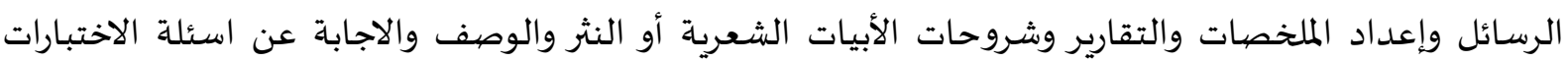
(شحاته، 2010؛ مدكور، 2006؛ وزارة التربية والتعليم، 2013)

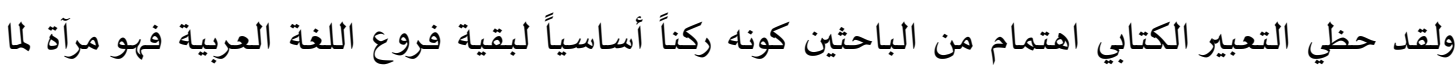
يجيش في عقول الطلاب من أفكار ومشاعر تظهر في كتاباتهم المثرية بتنوع أفكارهم ورصانة تعابيرهم الأدبية وتعينهم

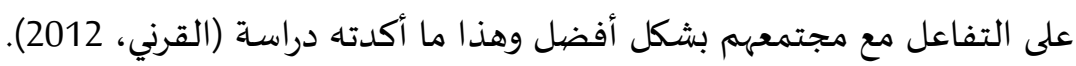

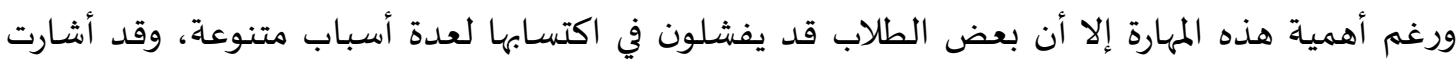

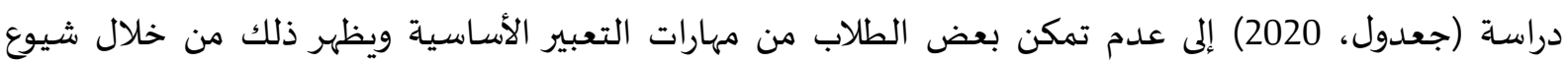

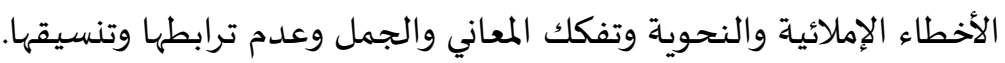

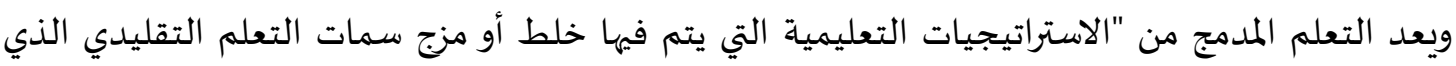

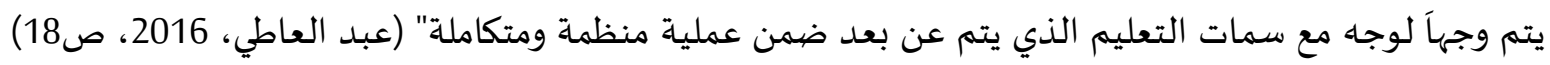


ولاستخدام التكنولوجيا أثر إيجابي في التعليم كما أكدت على ذلك دراسة (سلمان، 2018)، وتأتي أهميته في تنمية التحصيل وزيادة الدافعية لدى الطلاب نحو التعلم وتكوين اتجاهات إيجابية نحو استخدام المستحدثات

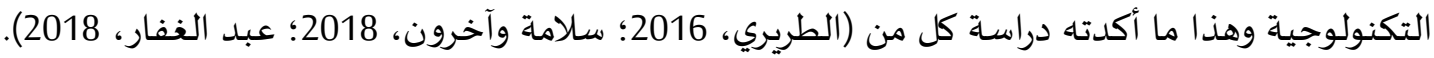

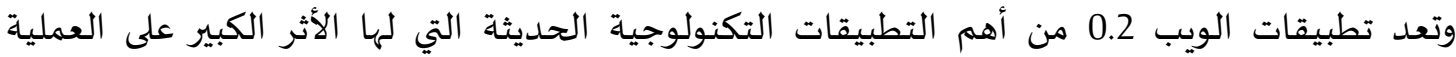

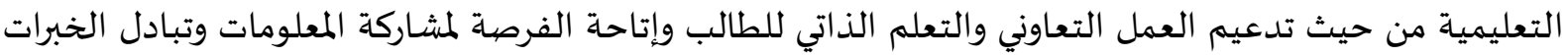
بين الطلاب ومن هذه التطبيقات: الويكي والبودكاست والمدونات وشبكات التواصل الاجتماعية (Grote, 2013).

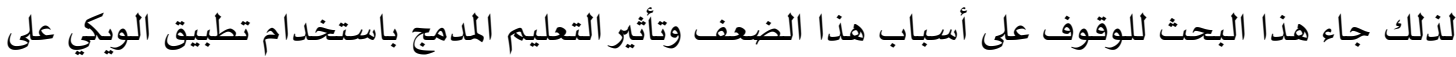
مهارة التعبير الكتابي على طلاب الصف السادس الابتدائي.

مشكلة الدراسة:

من خلال اهتمام الباحثة بمجال التعليم بشكل عام وما يختص بمجال القراءة والكتابة باللغة العربية على وجه التحديد ومن خلال ما يتم مناقشته مع مدرسي اللغة العربية بشكل دوري عن أهم التحديات والصعوبات التي يتعرض لها التدريس في هذا المجال، لاحظت الباحثة وجود تكرار لطرح موضوع تدني مستويات الطلبة في مهارة التعبير الكتابي، من أكثر معلمي مادة اللغة العربية في مدارس ومراحل دراسية مختلفة، ولهذا قامت الباحثة بإنشاء

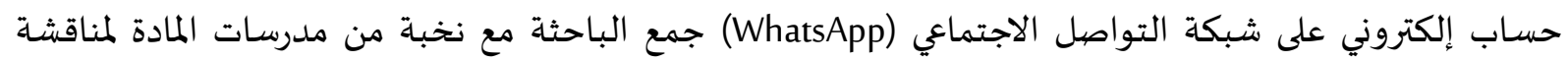

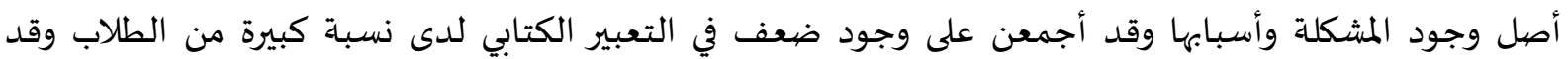

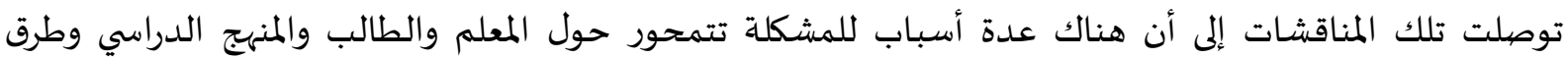

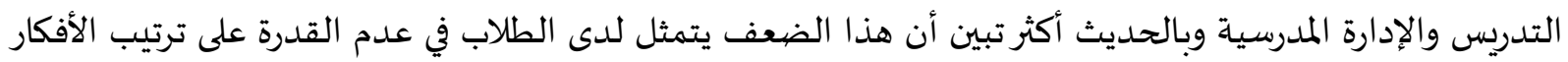

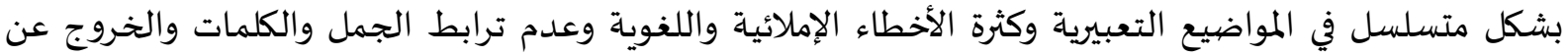

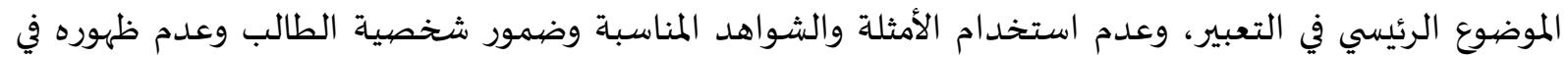

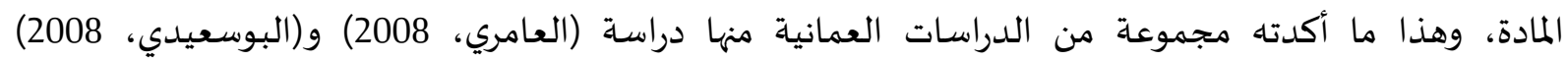
و(المياسي، 2012) والتي خلصت إلى وجود ضعف في مدى تمكن الطلاب من هذه المهارات، وكذلك أكد كل من

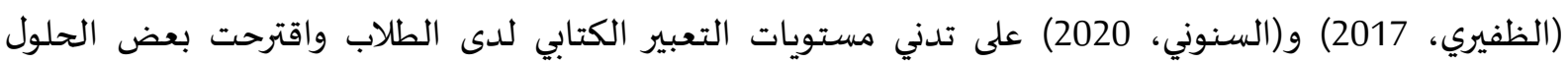

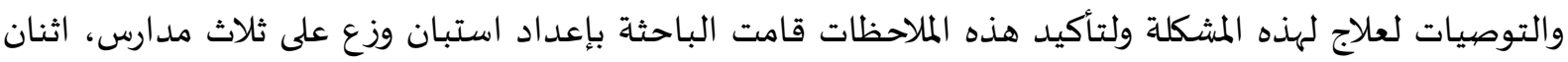

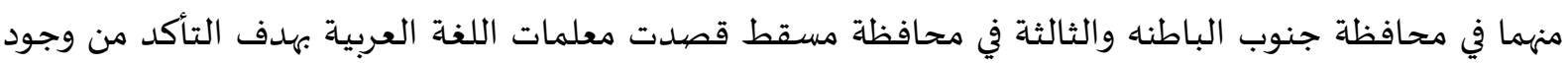
المشكلة وبيان أسباب الضعف في مهارة التعبير الكتابي من وجهاة نظرهن وبهدف استطلاع آرائهن حول المشكلة كونهن

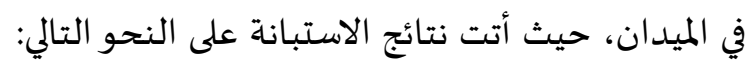
ترى 63\% من المعلمات أن أسباب الضعف فئس في التعبير الكتابي متداخلة بين المعلم والطالب والمنهج والأسرة

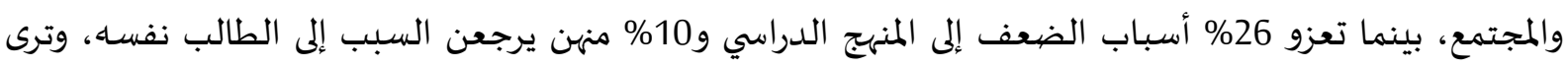

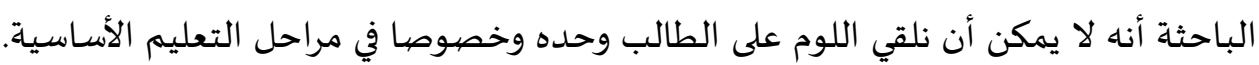

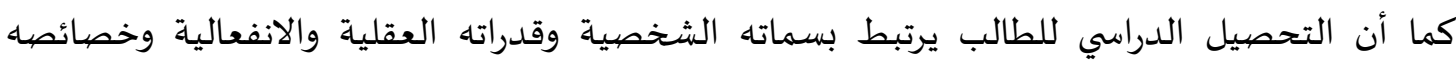

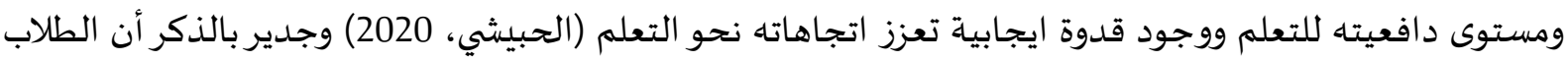
من ذوي صعوبات التعلم يحضيون برعاية خاصة ضمن برامج محددة من معلمات مختصات بصعوبات التعلم (مسافر ، 2020). 
وعند سؤال المعلمات عن مدى فاعلية المنهج الدراسي وهل هو معد بشكل جيد لتنمية مهارة التعبير الكتابي

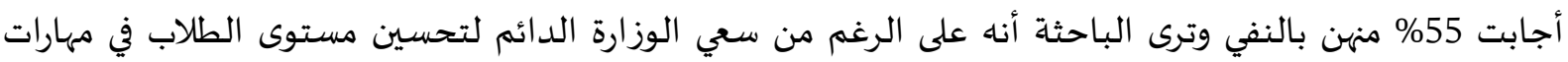

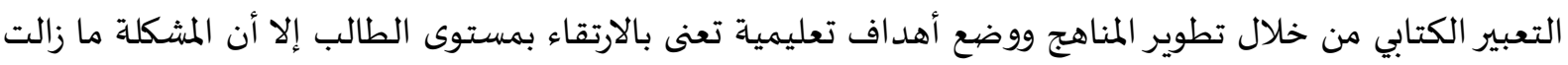
موجودة رغم تلك الجهود، لذلك ترى الباحثة أن المشكلة لا تكمن في المناهج كما ترى النسبة المذكورة من المعلمات

وترى 95\% من عينة الاستبانة بأن إدارة المدرسة لا تقوم بالدور المأمول في تعزيز مهارة التعبير الكتابي بإقامة

المسابقات الأدبية على مستوى المدرسة أو على مستوى المدارس والباحثة هنا غير مهتمة بالجانب الإداري.

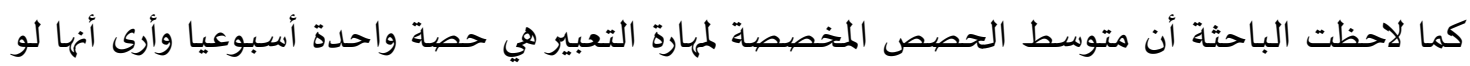
استغلت بشكل جيد وبدون إهمال لأتت ثمارها فعدد الحصص لا يعد سبب لضعف الطلاب في هذه المهارة بالإضافة إلى أن هذه المشكلة تعد إدارية وليست مجالاً للبحث.

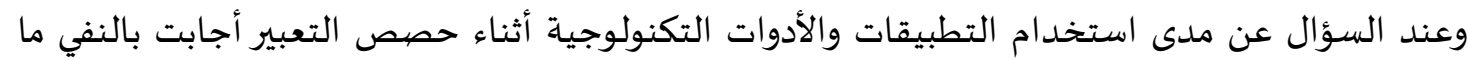
نسبته 65\%، بينما 10معلمات من أصل 18معلمة أجبن على سؤال ما أهم استراتيجيات وطرق التدريس التي تتبعها في تدريس مهارة التعبير باستراتيجية الحوار والمناقشة كاستراتيجية رئيسية بالإضافة إلى استراتيجية التعلم التعاوني

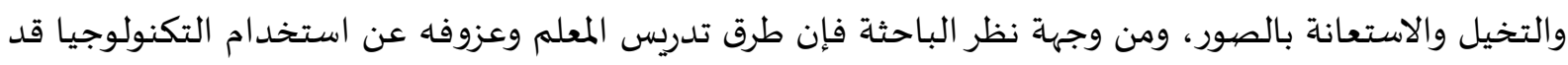

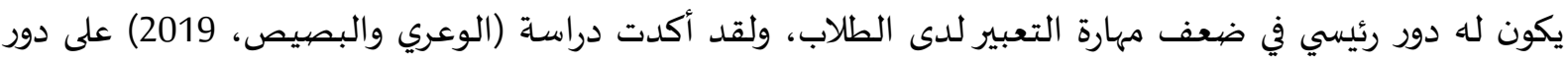

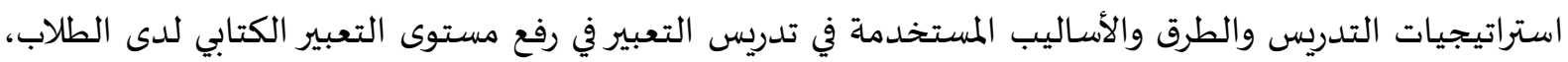

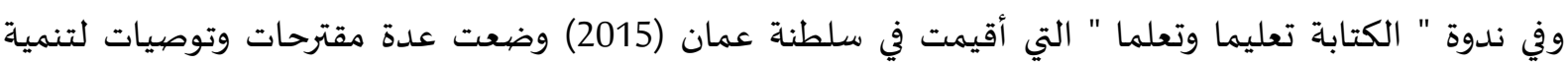

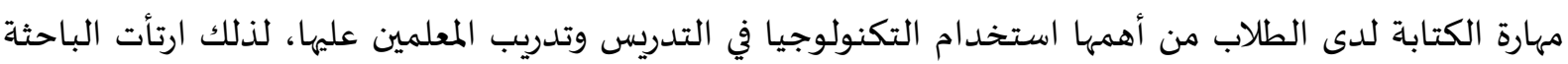

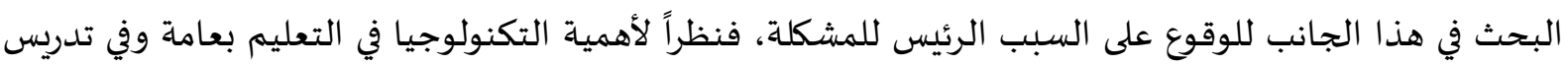

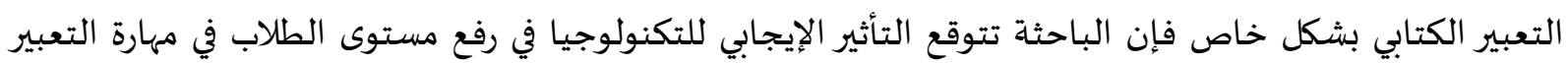

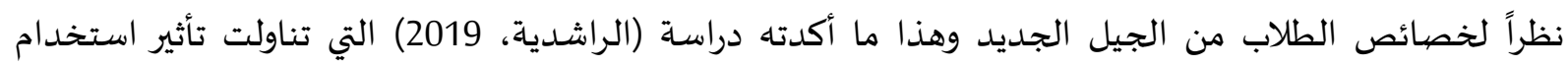

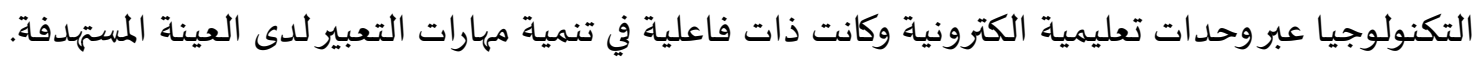

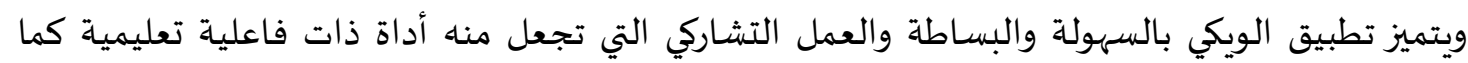

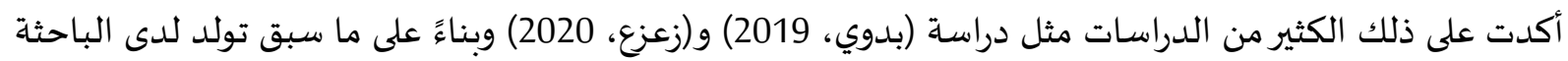
الإحساس بضرورة الوقوف على هذه المشكلة لذلك فإن هذه الدراسة ستعنى بالبحث عن فاعلية التعليم المدمج باستخدام تطبيق الويكي على مهارات التعبير الكتابي.

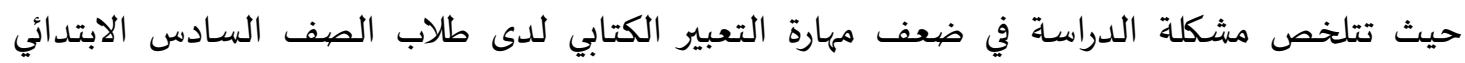

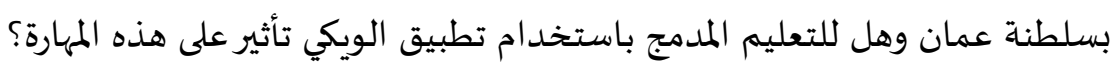

اسئلة الدراسة

ما فاعلية التعلم المدمج باستخدام الويكي في تنمية مهارات التعبير الكتابي لدى طلاب الصف السادس؟

الفروض:

1. يوجد فرق دال إحصائيا عند مستوى الدلالة (0.05) بين متوسطي درجات المجموعة التجريبية والضابطة في

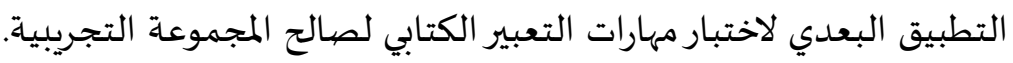




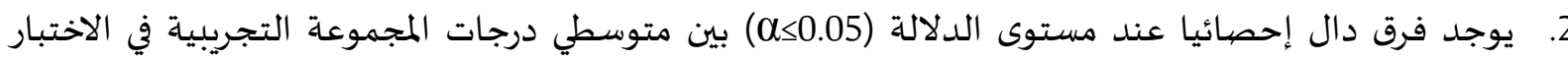
القبلي والبعدي. أهداف البحث

تهدف الدراسة إلى: البعاث 1. التعرف على مدى فاعلية التعلم المدمج باستخدام الويكي في تنمية مهارات التعبير الكتابي.

أهمية الدراسـة

من المؤمل أن تفيد هذه الدراسـة:

1. أصحاب القراروتحثهم على استخدام التعلم المدمج في المؤسسات التعليمية.

2. القائمين على إعداد مناهج اللغة العربية من خلال تضمين تطبيق الويكي سيبس في أدلة الدئ المعلم لتنمية مهارات التعبير الكتابي لطلبة الصف العداد منافي الثامن. 3. مشرفي اللغة العربية ومعلميها عن طريق تزويدهم بآلية تطبيق الويكي لتوظيفها في تنمية مهارات التعبير الكتابي. 4. الإفادة من معايير تصميم الباحثة لموقع الويكي وكيفية توظيفه في دروس التعبير المتعلقة بمنهج الصف

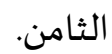
5. الإفادة من معايير تصحيح التعبير الكتابي التي أعدتها الباحثة.

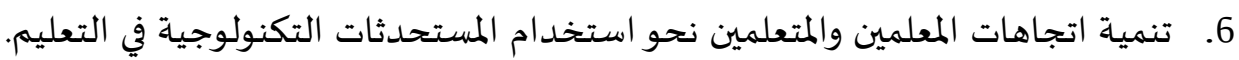

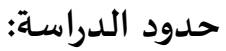
الحدود الموضوعية: فاعلية التعلم المدمج باستخدام الويكي في تنمية مهارات التعبير الكتابي.

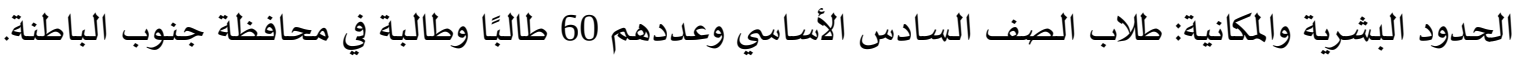

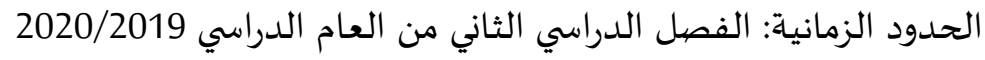

$$
\text { مصطلحات البحث }
$$

- التعبير الكتابي: عرفه مجاور (2000، ص222) بأنه:" إمكانية الفرد التعبير عن أحاسيساه وأفكاره ومشاعره في

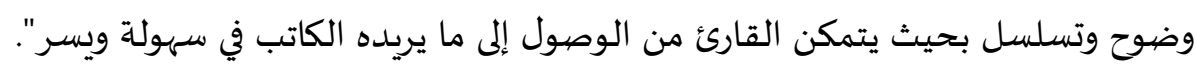

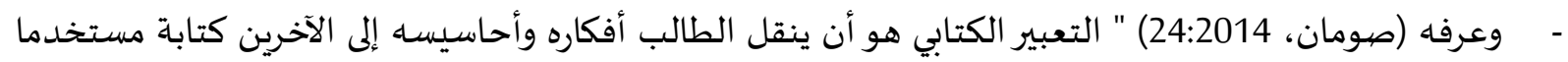

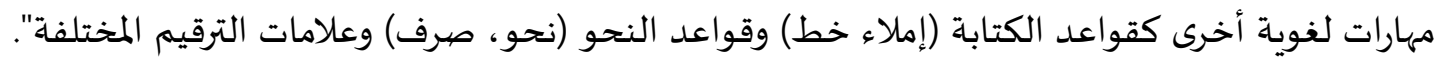

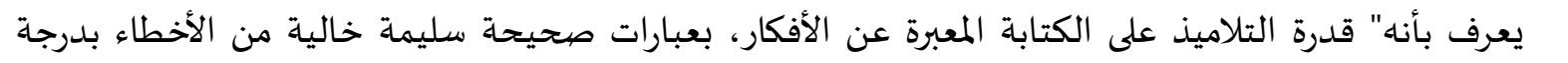

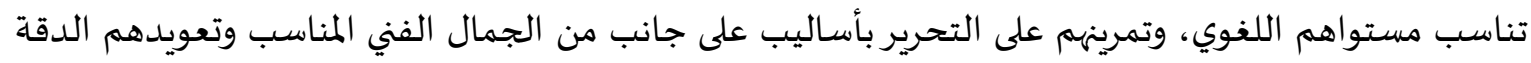

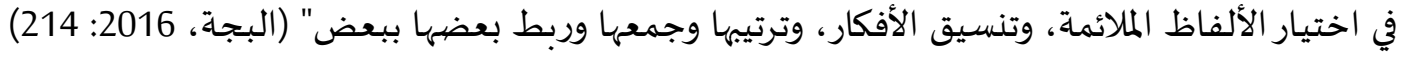

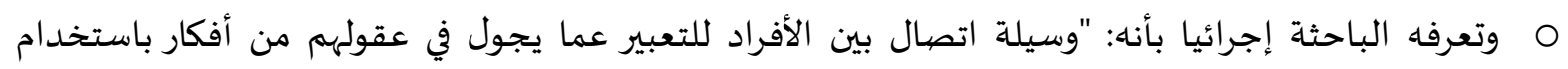

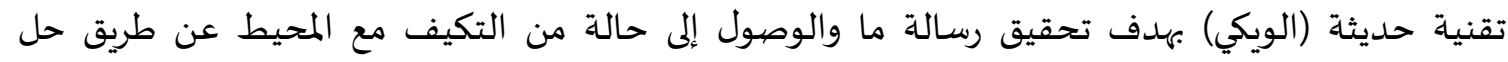

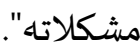


- التعلم المدمج: ويعرفه زيتون (2005: 17) بأنه: " إحدى صيغ التعلم التي يندمج فيها التعلم الإلكتروني مع التعا التعلم الصفي التقليدي في إطارواحد، حيث توظف أدوات التعليم الإلكتروني سواء المعتمدة على الكمات الكمبيوتر أو على الشبكة في الدروس".

O متعرفه الباحثة بأنه: " استخدام التكنولوجيا الحديثة متمثلة في تطبيق الويكي في الغرفة الصفية في الموقف

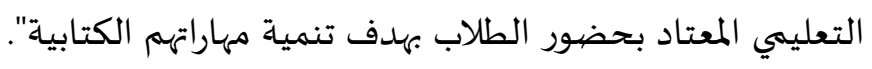

- الويكي: ويعرف بأنه: " أحد تطبيقات web2,0 ويعد تطبيق لإدارة محتوى صفحات يمكن إضافتها وتحريرها وتعديلها من قبل المستخدم دون أي قيود فيما يشبه التأليف المشترك" (عبد العاطي، 2015، صوانسيقان O وتعرفه الباحثة إجرائيا بأنه: " تطبيق إلكتروني يسمح للمعلم بإضافة روابط وصور ومقاطع فيديو خاصية بمادة التعبير الكتابي تساعد الطلاب على تنمية مهاراتهم في التعبير الكتابي بشكل تعاوني".

2. الإطار النظري والدراسـات السـابقة

أولا- التعبير الكتابي

صور التعبير الكتابي

للتعبير الكتابي عدة صور وهي كما عددها السفاسفة (2011، ص180):

كتابة الأخبار

الإجابة الكتابية عن الأسئلة بعد القراءة الصامته

التعبير الكتابي عن الصور

كتابة المذكرات واليوميات والتقارير

تلخيص القصص كتابة

إعداد الكلمات لإلقائها في المناسبات

كتابة الرسائل بأنواعها

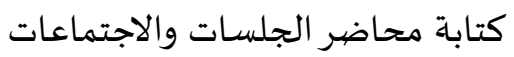

نثر الأبيات الشعرية وكتابتها

تأليف قصص في غرض معين أو تكملة قصص ناقصة أو تطويل قصص قصيرة.

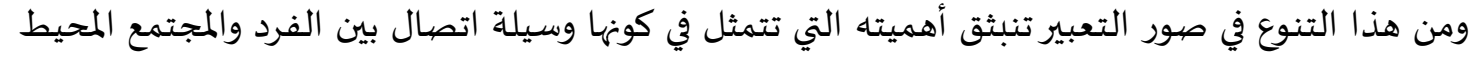

باه فلا بد أن تكون هذه الوسيلة واضحة وصحيحة وخالية من التشويش (عاشور ومقدادي، 2005).

$$
\text { مجالات التعبير الكتابي: }
$$

وتظهر أهمية التعبير من خلال اربعة مجالات:

1. المجال الشخصي: وتساعد الطالب على صقل شخصيته وتحقيق ذاته واستثمار قدراته ومواهبه.

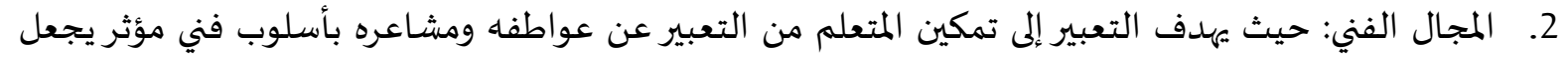

القارئ يتفاعل ويستمتع بهذا الفن. 
3. المجال الاجتماعي: وذلك من خلال الأثر الرئيس للتعبير في تسجيل التراث الإنساني وربط حاضر الشعوب

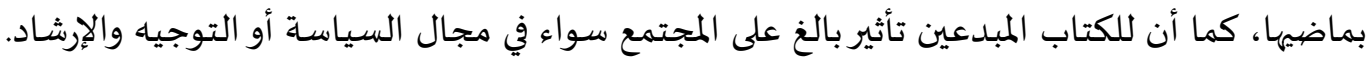
4. المجال التربوي: فالتعبير يتيح الفرصة أمام الطلاب على البوح بأفكارهم مع الحرص على تنظيمها وانتقاء

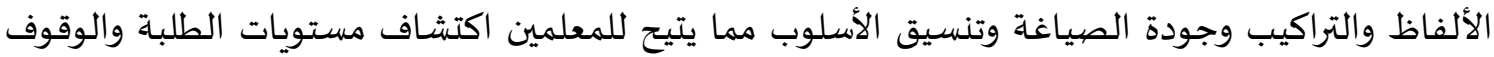

على مواطن الضعف ومعالجتها وتشجيع الموهوبين ليكونوا أدباء المستقبل. (جاد، 2016؛ البجة، 2016)

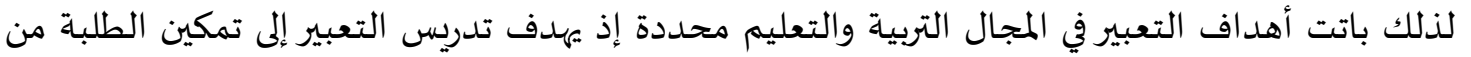
التعبير عن أفكارهم ومشاعرهم وحاجاتهم بشكل صحيح، كما يهدف إلى تزويدهم بالألفاظ والتراكيب التي تبني

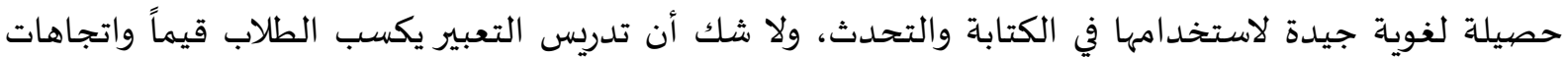
ومعارف إيجابية نحو نفساه ووطنه ودينه ومجتمعاه وتهيؤه لمواجهة المواقف الحياتية وتعينه على استخدام حواساه بالشكل السليم؛ مما ينهي من مهاراته العقلية المتنوعة، ويهدف أيضا إلى تعويد الطلاب على ترتيب الأفكار وتنظيمها

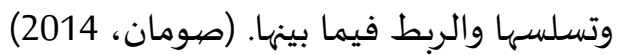

أسس التعبير الكتابي: ولكي يحقق المعلم الأهداف السابقة يجب عليه مراعاة مجموعة من الأسس اثناء تدريسه للتعبير ومن هذه أهم هذه الأسس:

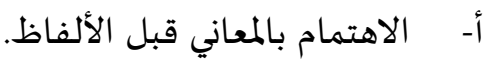
ب- إتاحة الفرصة للطلاب باختيار الموضوعات تمثل اهتماما أكبر لدهيهم وتتصل بخبراتهم وخاصة الخبرات المباشرة وتتناسب مع مستواهم العمري والمعرفي.

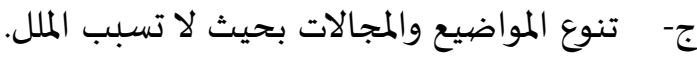
د- مناقشة أفكار الموضوع والتحدث حوله قبل الشروع في الكتابة. هـ- تخطيط الموضوع وتقسيما إلى مقدمة وعرض وخاتمة بحيث تسهل العملية للطلاب.

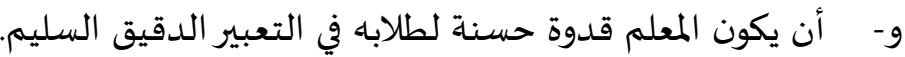
ز- لزوم ربط التعبير الكتابي ببقية فروع اللغة العبية واستثمارها في التدربب على مهارات التعبير. ح- مراعاة الفروق الفردية وذلك بزيادة تدريب الطلاب ذوي المستويات الضعيفة وإبراز مهارات الطلاب ذوي المستويات المتقدمة.

ط- الحرص على تزويد الطالب بمهارات جديدة كل حصة مع ضرورة تثبيت المهارات السابقة.

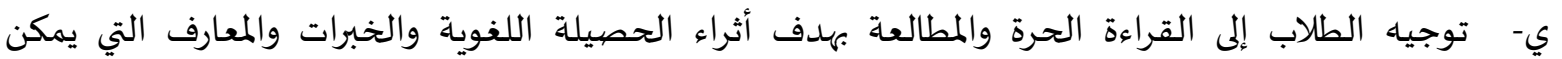

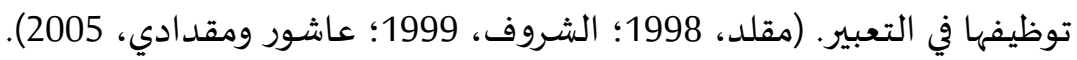

$$
\text { مهارات التعبير الكتابي: }
$$

ولكي يحقق التعبير الكتابي أهدافه لابد أن يتحلى الطالب بعدة مهارات أساسية، ولقد تعددت تقسيمات الباحثين والمتخصصين لمهارات التعبير الكتابي فقد قسمها الراميني (2007) كالآتي: 1. مهارات عامة تتضمن صحة الرسم الإملائي، سلامة النحو والصرف، دقة توظيف الاقتباسات، كتابة الترابية

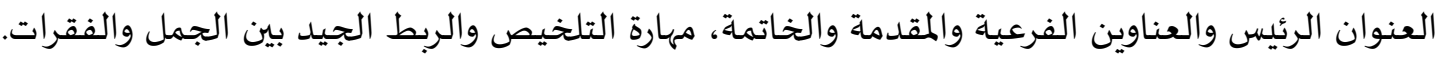

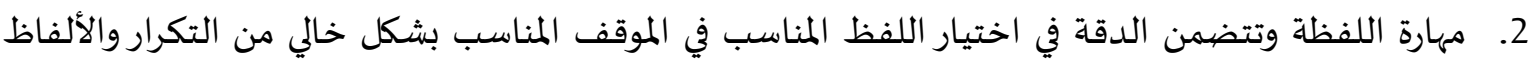
العامية. والمهارة الثالثة هي مهارة الجملة وتتضمن اختيار الجمار الجمل المناسبة وسلامة تركيبها وترتيبها. 
3. مهارة الفكرة من حيث وضوحها وتنوعها وتسلسلها ودعمها بالأدلة والبراهين.

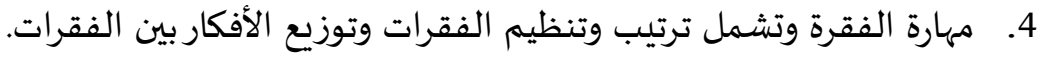

وترى الباحثة أن تمكن الطلاب من هذه المهارات يعد ضرورياً لمساعدة الطلاب علئ على التعبير عن أفكارهم

بدقة ووضوح وعلى تنمية قدراتهم العقلية واللغوية.

من خلال ملاحظة أعمال الطلاب في دروس التعبير تتضح مظاهر الضيعف في التعبير الكتابي، ومن الملاحظ

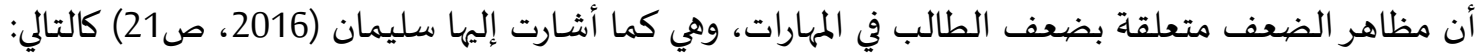

1. إهمال ترتيب الأفكار بطريقة منطقياة.

2. التواء العبارات واضطراب الأسلوب مما يصعب على القارئ فهم المقصود.

3. ضحالة والأفكاروعدم التركيز على الفكرة الرئيسية.

4. ضعف الطالب في القدرة على ربط الفقرات والأفكار.

5. عدم استخدام أدوات ربط مناسبة.

6. كثرة الأخطاء النحوية والإملائية.

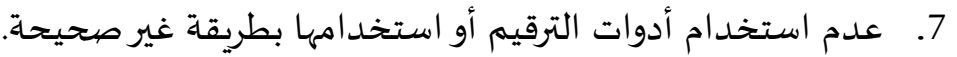

أسباب الضعف في التعبير الكتابي:

نلاحظ أن أسباب الضعف متنوعة وتعزى إلى العديد من العوامل والأسباب المتشعبة وفيما يلي تفصيل

لبعض الأسباب، بحيث يمكن تصنيفها كما صنفها القطيطي (2017) إلى:

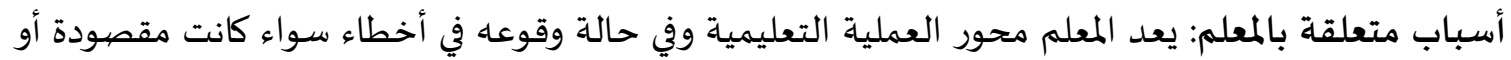

غير مقصودة فإن ذلك يؤثر على أداء الطلاب منها:

1. أن بعض معلمي اللغة العربية لا يربطون فروع اللغة العربية والأنشطة المدرسية بالتعبير للاستفادة منها.

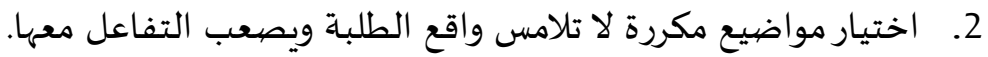

3. إهمال بعض المعلمين لحصص التعبير وعدم استغلالها لتنمية مهارات التعبير لدى الطلاب.

4. عدم التنوع في استراتيجيات التدريس.

ولقد أكدت دراسة العتيبي (2019) أن استخدام استراتيجيات تكنولوجية حديثة يؤثر إيجابيا في تنمية

مهارات التعبير، حيث أكدت الدراسة فاعلية استراتيجية الصف المقلوب التي تعتمد على التقنية والانترنت في تنمية

هذه المهارات.

كما أكدت دراسة عليان (2018) على أهمية الاستراتيجيات الحديثة في تنمية مهارات التعبير الكتابي

والشفوي، فقد قامت الباحثة بدراسة أثر القصص المصيورة المحوسبة وتوصلت نتائج دراستها إلى وجود فروق ذات

دلالة إحصائية لصالح التطبيق البعدي للعينة التجريبية التي خضعت للتدريس باستخدام الاستراتيجية.

- عدم متابعة أعمال الطلاب لتقديم التغذية الراجعة المناسبة واستخدام اساليب تصحيح غير سليمة كالاكتفاء

بالنظر أو الشطب على الأخطاء الإملائية. (مقلد، 1998)

أسباب متعلقة بالطالب نفسه: قد يقوم التلميذ ببعض الممارسات التي من شأهها أن تضعف مهارة التعبير منها:

1. قلة القراءة والمطالعة الحرة التي قد تثري من حصيلة الطالب اللغوية والأفكار المتجددة.

2. ابتعاد الطالب عن الأنشطة اللغوية المدرسية كالاشتراك في الإذاعة أو الصحافة المدرسية. 
أسباب متعلقة بالأسرة والمجتمع: فبعض الأسر لا تتيح لأبنائها فرصًا للحوار والمناقشة وتحرمهم من الاختلاط

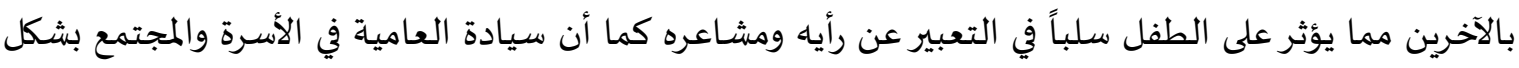

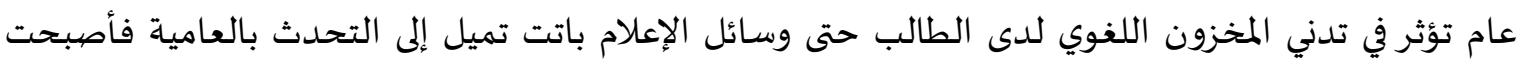
تؤثر سلبا أيضا على الطفل (البجاه، 2007). وترى الباحثة أن الاستراتيجيات التي يتبعها المعلم تعد من أهم أسباب الضعف الفيجة كما ذكرنا ذلك سابقاً لذلك

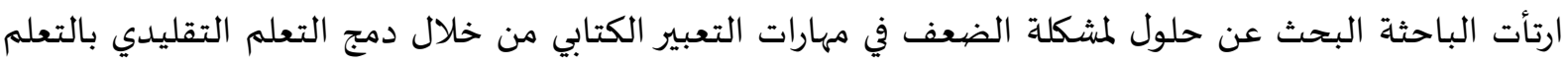

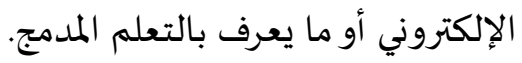

ثانيا: التعلم المدمج تم نقل التعاريف متطلبات بيئة التعلم المدمج: ولبيئة التعلم المدمج عدة متطلبات حددها محمدمد (2020) فيما يلي:

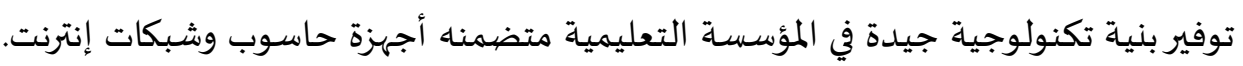
تدريب كل من المعلمين والمتعلمين ليتمتعوا بمهارات جيدة في التعامل مع التكنولوجيا. تصميم المناهج بما يتناسب مع هذا النوع من التعليم. أن يصبح المعلمون مرشدين وموجهين للعملية التعليمية قادرين على تصميم البرامج المناسبة للعملية التعليمية. وترى الباحثة أن أغلب مدراس السلطنة تتمتع ببيئة ملائمة للتعلم المدمج حيث تم تجهيز المدارس بأجهزة حواسيب وشبكات إنترنت، كما تقام دورات تدريبية بشكل دوري للمعلمين في جميع التخصصيات.

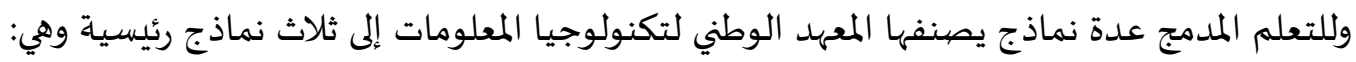

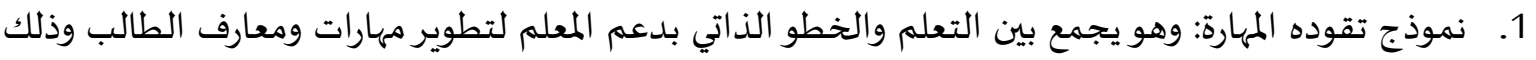

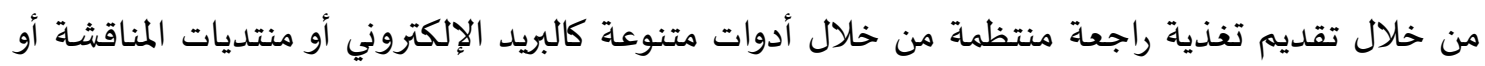
وجهاً لوجها في اللقاءات التقليدية. 2. نموذج يقوده الاتجاه: الذي يدمج أدوات ووسائل متنوعة بهدف تعزيز اتجاهات وسلوكيات محدده لدى الطلاب. 3. نموذج تقوده الكفاءة: وهو يدمج أدوات دعم الأداء مع مصادر إدارة المعرفة والاستشارات لتطوير كفاءات

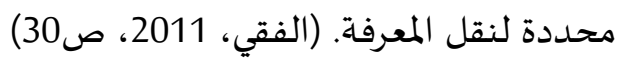

وسوف تتخذ الباحثة من التصنيف الأول نموذجاً يتم العمل باه في هذا البحث وذلك باستخدام تطبيق

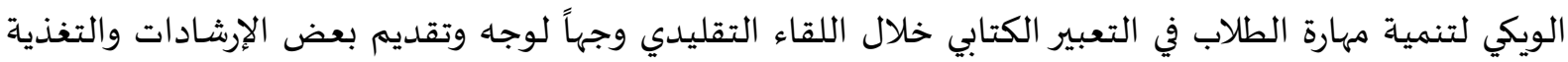
الراجعة المباشرة للطلاب. وفي دراسة أجراها الظفيري وآخرون (2017) بعنوان "أثر استخدام التعلم المدمج في علاج صعوبات القواعد

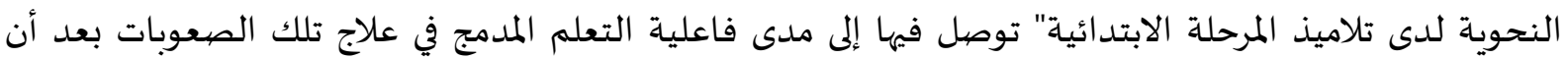
قام بإجراء تجربة الدراسة على عينة تكونت من 40 طالباً ممن يعانون من صعوبات في تعلم القواعد النحوية وتم تقسيمهم إلى مجموعتين بطريقة عشوائية لإجراء تجربة البحث. 
وللتعلم المدمج عدة مميزات وأهمها رفع التحصيل الدراسي والمعرفي للطلاب وزيادة قدرتهم على تطبيق أساليب التعلم وتوسيع خبراته، وقد تناولت دراسة (سعيد، 2020) برنامج قائم على التعلم المدمج لعلاج صعوبات واهيات

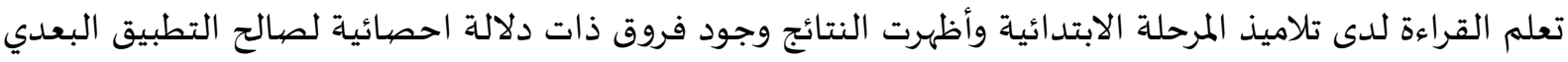

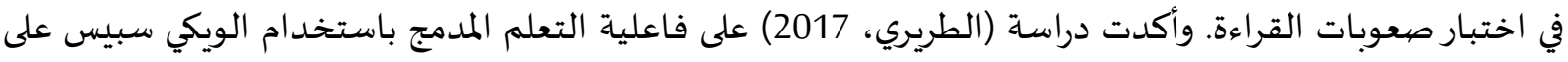
تنمية مهارات كتابة الإملاء لدى طلاب الصف الخامس الابتدائي وقد تكونت عينة البحث من (60) طالباً تم

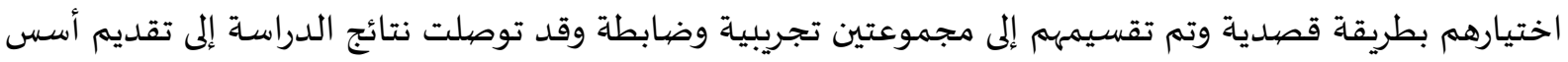

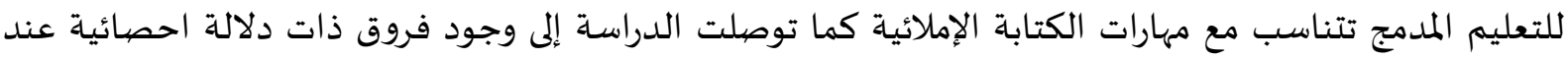

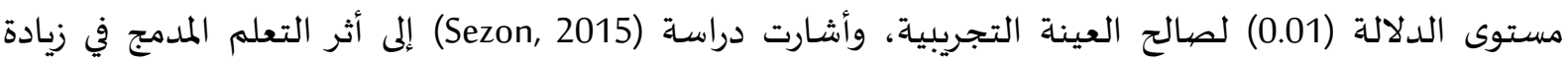
التحصيل اللغوي وزيادة المفردات باللغة الإنجليزية.

ثالثا: الويكي

اختارت الباحثة تطبيق الويكي لدمجاه مع العملية التعليمية التقليدية لمناسبة خصائصها مع مشكلة البحث، ولقد تعددت تعريفات الويكي في الأدبيات فقد عرفه الحلفاوي (2015، ص566) بأنه "موقع عبر الإنترنت تم بناؤه بطريقة من شأنها أن تسمح للمتعلمين بالتغيير الدائم للمحتوى من خلال العمل الجماعي في التأليف والتعديل وبالاعتماد المحدود على لغة Html. إن الفلسفة التي يقوم عليها العمل على منصات الويكي تهدف إلى تعزيز العمل التشاركي والجماعي والتفاعل بين الطلاب وتنمية مهارات تبادل الأفكاروالمعرفة لذلك تظهر للويكي عدة فوائد تعليمية وهي كما ذكرها كل من (عبد إند العاطي، 2015؛ عجينة، 2016):

تطوير مهارات الكتابة والقراءة وفهم المعلومات من خلال التدقيق فيها وتصحيح الأخطاء. تطوير طرق التعبيروالتواصل عن طريق مجموعة من الوسائط المتعددة. تنمية المهارات اللغوية حيث تساعد الويكي على صقل مهارات التعبير والقراءة خلال تحرير المقالات. ولقد أشارت دراسة (لمياء، 2017) إلى فاعلية التدريس باستخدام الويكي على تنمية مهارات كتابة المقال الأدبي. تنمي لدى الطلاب مهارات التعلم النشط، كما تنهي التفكير الناقد لديهم والمهارات الذهنية الأخرى كالتحليل والتركيب وحل المشكلات.

تكسب الطلاب حس المسؤولية والالتزام بالتوجيهات المحددة ومهارات العمل الجماعي. وفي دراسة قام بها الظفيري (2017) لمعرفة فاعلية التدريس باستخدام محررات الويكي التعاونية والتنافسية على تنمية مهارات الدراسات الاجتماعية، حيث تكونت عينة البحث من (60) طالباً بالصف السات السابع في مدينة الجهراء بالكويت حيث قسمت العينة إلى مجموعتين المجموعة الأولى درست باستخدام محررات الويكي مهيك

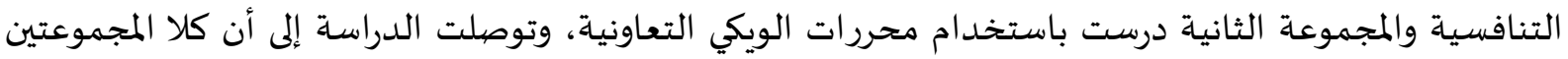
تأثرت بزيادة التحصيل المعرفي. وترى الباحثة أن تطبيق الويكي يعد الأنسب لمشكلة التعبير الكتابي إذ تعد تطبيقات الويكي التعليمية من

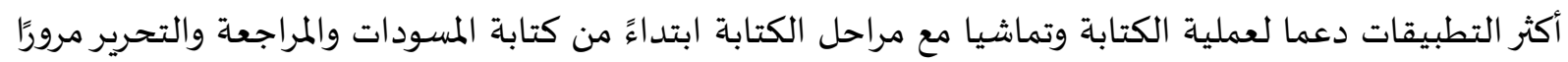

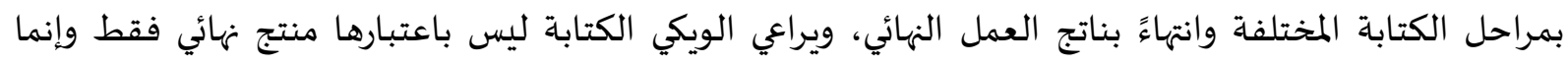


Parke, Chao, باعتبار الكتابة عملية يقوم بها الطلاب بشكل تعاوني وتشاركي بين بعضهم البعض وبينهم وبين المعلم

كما أكدت دراسة (العجمي، 2019) على أهمية وأثر استخدام تطبيق الويكي في تنمية مهارات الكتابة في اللغة الإنجليزية لدى طالبات الصف التاسع حيث تكونت عينة الدراسة من (38) طالب قسمت إلى مجموعتين تجريبية وضابطة وقد أظهرت النتائج وجود فروق ذات دلالة إحصائية لصالح المجموعة التجريبية.

3. منهجية البحث وإجراءاته.

منهج البحث:

اتبعت الباحثة في هذا البحث المنهج شبه التجريبي الذي يهدف إلى معرفة أثر التعليم المدمج باستخدام

تطبيق الويكي وهو المنهج الأكثر مناسبة وشيوعا في موضوعات البحت تكنولوجيا التعليم.

مجتمع البحث وعينته:

تكون مجتمع الدراسة من جميع طلاب التعليم الأساسي بالمدارس التابعة للمديرية العامة للتببية والتعليم

بمحافظة جنوب الباطنة في الفصل الدراسي الثاني من العام الدراسي 2019/2018. البالغ عددهم (4602) طالباً وطالبة (وزارة التربية والتعليم)

وقد اختيرت مجموعتا الدراسة من مدرسة عاتكة بنت أبي صفرة ومدرسة كعب بن سور، حيث مثلت

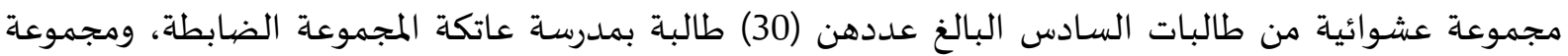
عشوائية من طالبات السادس من نفس المدرسة البالغ عددهم (30) المجموعة التجريبية، وقد اختيوت المبات المدرستين

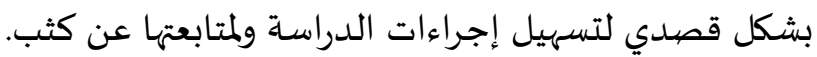

متغيرات البحث:

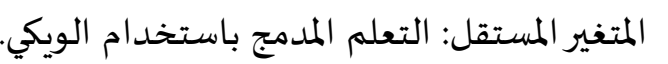

المتغير التابع: مهارة التعبير الكتابي.

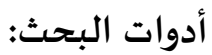

قامت الباحثة بالاستعانة باختبار تحصيلي في مهارات التعبير الكتابي تم تطبيقه قبل تدريس الوحدة وبعد

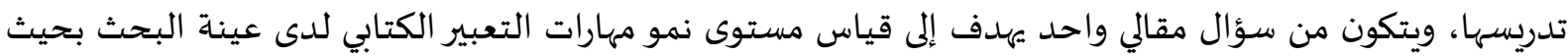

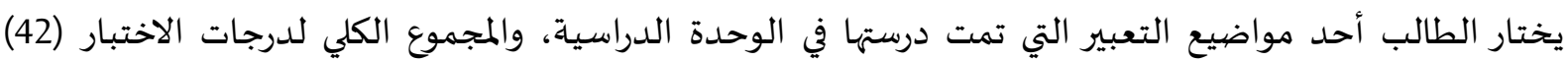

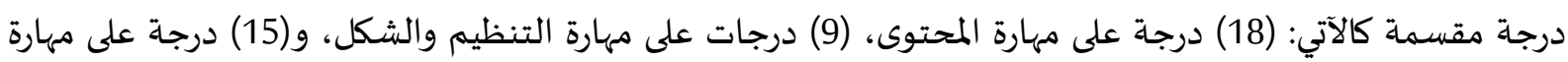
اللغة والأسلوب، وقد تم التحقق من صدق الاختبار الظاهري عن طريق عرضها على مجموعة من المحكمين، وتم الماته حساب صدق الاتساق الداخلي عن طريق تطبيقه على عينة استطلاعية من خارج عينة الدراسة تكونت من من (28)

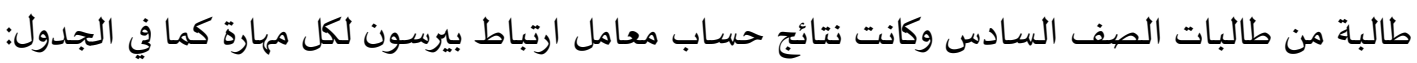
جدول (1) حساب معامل ارتباط بيرسون لاختبار مهارات التعبير الكتابي
اللغة والأسلوب
التنظيم والشكل ميارات التعير
المحتوى المباه يرسيون
المهارة
0.085
0.084
0.87

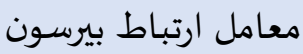




\begin{tabular}{|c|c|c|c|}
\hline اللغة والأسلوب & التنظيم والشكل & المحتوى & المهارة \\
\hline 0.036 & 0.031 & 0.028 & القيمة الاحتمالية (SIG) \\
\hline
\end{tabular}

الارتباط دال احصيائيا عند مستوى الدلالة $05.0=0.0$

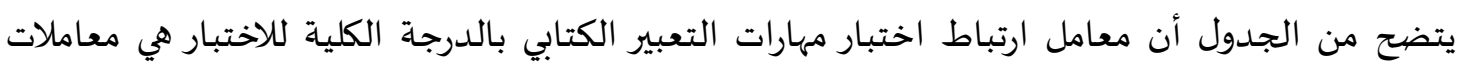

ارتباط مناسبة لأغراض الدراسة الحالية.

وتم التحقق من ثبات الاختبار عن طريق تطبيق الاختبار وإعادة الاختبار على عينة استطلاعية بلغ عددها الإها

(28) طالبة بخلاف العينة الهائية، ومن ثم تم حساب معامل ارتباط بيرسون بين تقديراتهم في المرتين إذ بلغ (0.86) وهي قيمة دالة عند مستوى الدلالة (0.01) وهي قيمة عالية يمكن الاعتماد عليها في تطبيق الاختبار الحالي.

\section{المعالجة التجريبية للمتغير المستقل:}

قامت الباحثة بتصميم صفحة ويب على تطبيق الويكي خاص بدرس الوصفئفئفي في التعبير الكتابي كما هو

مقرر في مادة اللغة العربية في الصف السادس الابتدائي وقد اتبعت الباحثة الخطوات الإجرائية التالية مستندة إلى فئل

مراحل التصميم التالية:

جدول (2) الخطوات الإجرائية لتصيميم صفحة ويب لتطبيق ويكي خاص بدرس الوصف في التعبير الكتابي

3 مرحلة التطوير - إعداد السيناريوهات

التخطيط للإنتاج- التطوير - عمليات التقويم البنائي

4)مرحلة النشروالاستخدام والمتابعة

النشر

التنفيذ (التوظيف والاستخدام)

التثبيت والدمج

المتابعة والاستمرار
2)مرحلة التصهيم

تصميم الأهداف التعليمية وتحليلها

وتصنيفها

تصميم أدوات القياس محكية المرجع

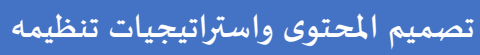

تصميم سيناريو استراقيجيات التفاعلات

التعليمية الستراتيكات

ت تحديد نمط التعليم وأساليبه

\section{1) مرحلة التحليل} تحليل المشكلة وتقدير

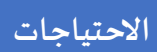

تحليل خصائص المتعلمين

تحديد المهمات التعليمية

تحليل الموارد والقيود في المينات التمليعية

البيئة

وتخضع جميع هذه المراحل لعمليات تعديل مستمرة.

وقد مر التصميم التعليمي بالمراحل التالية:

أولا: مرحلة التحليل

1. تحليل المشكلة: مرحه

حيث تم دراسة العوامل التي أدت إلى تدني مستوى مهارات التعبير الكتابي لدى طلاب الصفف السادس وتمكنت الباحثة من الوصول إلى أن استخدام الطرق التقليدية قد تكون سببا في هذه المشكلة ومن هنا برزت المارت الحاجة لاستخدام التقنيات الحديثة ومنها الويكي لتعزيز العملية التعليمية.

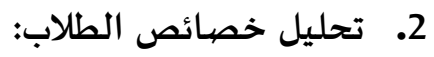

حيث تمت دراسة مدى توفر مهارات استخدام الحاسوب للطلاب، والرغبة القوية للدراسة عن طريق الدهابق

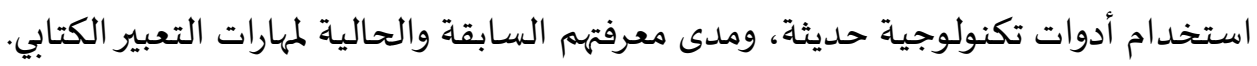

\section{3. تحليل المهمات التعليمية:}

حيث تم تحديد الأهداف السلوكية وتجزئتها إلى مستويات تفصيلية المهيلة كالآتي: 1- أن يصف الطالب المطلوب وصفه في مقاطع وصفيه صحيحه.

2- أن يوظف الطالب الروابط اللفظية والأساليب المناسبة للنص الوصفيه وصفيه 


\section{3- أن يستخدم الطالب علامات الترقيم المناسبة استخدامًا صحيحا. 4. تحليل الموارد والقيود في البيئة التعليمية:}

حيث تم التأكد من فاعلية معمل الحاسوب في المدرسة المعنية بالتطبيق التجريبي وتوصيلها بشبكة الإنترنت وتمكن الطلبة من الدخول لموقع الويكي.

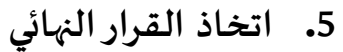

من خلال خطوات التحليل السابقة تم اتخاذ القرار الهائي بشأن استخدام الويكي لتنمية مهارات التعبير الكتابي لدى عينة البحث التجريبية.

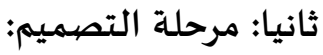

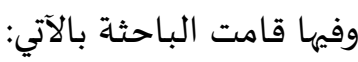
1- تنظيم المحتوى من حيث تحديد النشاط المتبع بما يحقق الأهداف التعليمية. 2- تصميم أداة القياس التي تمثلت في اختبار تحصيلي تم اثبات صيدقاه وثباته. 3- تحديد نمط التعلم وأسلوبه: وبذلك تم توظيف نمط التعلم التعاوني لجعل الطلاب يتشاركون فيما بينهم

بالتحرير.

4- تحديد طريقة تقويم الطلاب وهي عن طريق متابعة إضافاتهم وتعديلاتهم على صفحة الويكي. 5- تصميم سيناريو برمجية الويكي: وذلك بناء على الأهداف التعليمية التي تسعى الباحثة إلى تحقيقها. 6- اختيار مصادر التعلم المتعددة: حيث تم اختيار الوسائط المناسبة لدرس الوصف من صور ومقاطع فيديو تحفز الطالب على التعبيروإدراجها في موقع الويكي. ثالثا: مرحلة الإنتاج والتطوير

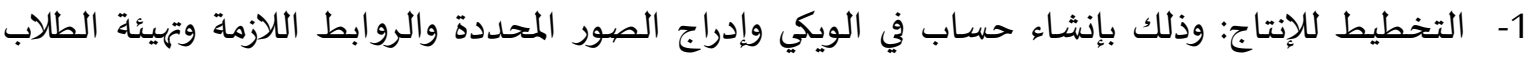
لدخول الويكي قبل بدء التجربة بوقت كاف والتأكد من سلامة الأجهزة المستخدمة.

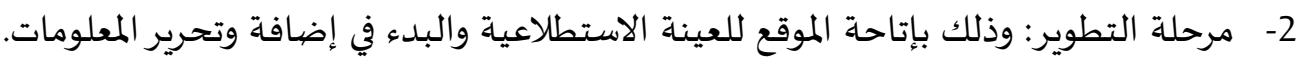

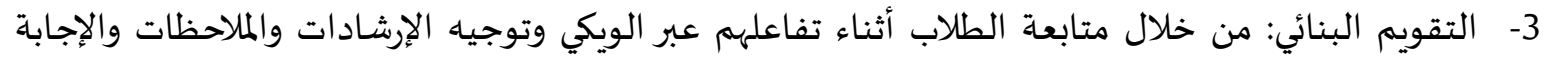
عن استفساراتهم. 4- التشطيب والإخراج النهائي: بعد الانتهاء من عمليات التقويم البنائي قامت الباحثة بإجراء بعض التعديات

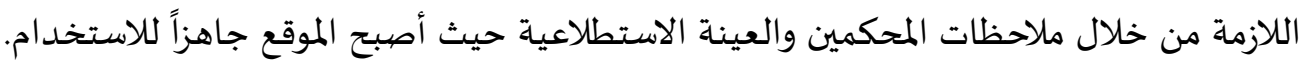
رابعا: مرحلة التقويم: وهدفت هذه المرحلة إلى قياس فاعلية التطبيق في تحقيق الأهداف التي وضعت من

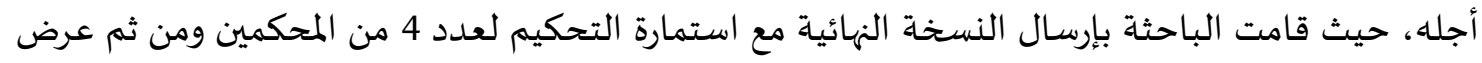
موقع الويكي على مجموعة من المتعلمين. خامسا: مرحلة النشر والتنفيذ والدمج والمتابعة: تم في هذه المرحلة إتاحة موقع الويكي للعينة التجريبية وبدء التحريروالإضافة والتعديل. مرحله التشرويل

\section{تجربة البحث (تكافؤ المجموعتين)}

للتأكد من تكافؤ المجموعتين قامت الباحثة بإجراء اختبار تحصيلي (ت) قبلي لموني لمهارات التعبير الكتابي للتأكد من تكافؤ المجموعتين التجربيية والضابطة، حيث يوضح الجدول المتوسطات الحسابية والانحرافات المعيارية وقيمة (ت) للمقارنة بين درجات المجموعة الضيابطة والتجريبية. 
الجدول (3) المتوسطات الحسابية والانحرافات المعيارية وقيمة (ت) للفروق بين المجموعتين الضابطة

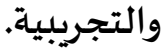

\begin{tabular}{|c|c|c|c|c|c|c|}
\hline الدلالة & قيمة ت & درجة الحرية & الانحراف & المتوسط & العدد (ن) & المجموعة \\
\hline غير دالة عند & \multirow{2}{*}{2.046} & \multirow{2}{*}{58} & 0.16971 & 34.57 & 30 & التجريبية \\
\hline مستوى 0.05 & & & 0.40305 & 30.33 & 30 & الضيابطة \\
\hline
\end{tabular}

يتضح من الجدول أن قيمة (ت) غير دالة إحصائيا لدى مستوى الدلالة (0.05)ألفا مما يدل على عدم وجود فرق ذي دلالة إحصائية بين متوسطي درجات المجموعتين التجريبية والضابطة في التطبيق القبلي لاختبار

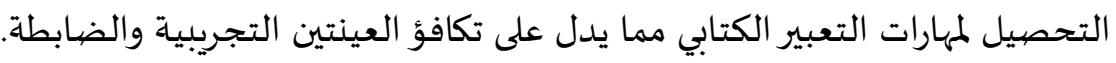

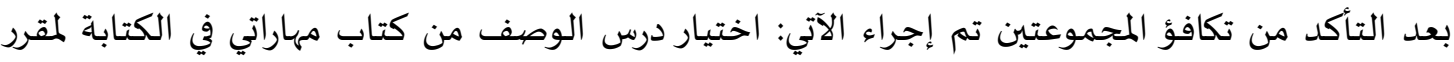
اللغة العربية للصف السادس الابتدائي، وقد قامت الباحثة بتطبيق الاستراتيجية على العينة التجريبية ابتداء من

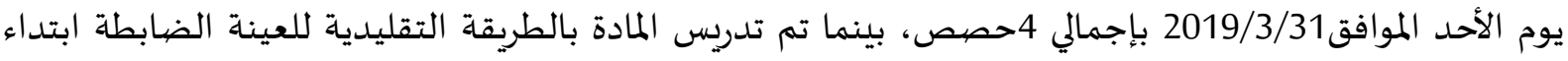
من يوم الاثنين الموافق 2019/3/25 بإجمالي 4حصص.

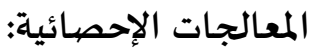

بعد الانتهاء من تدريس المجموعتين طبقت الباحثة اختبار مهارات التعبير الكتابي البعدي بتاريخ

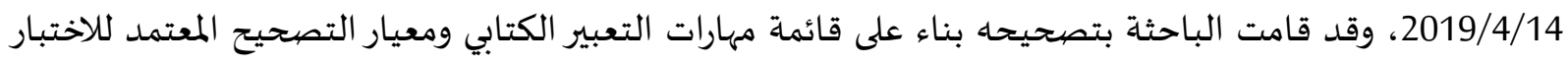

ثم تم إدخال البيانات في برنامج الرزم الإحصائية (spss).

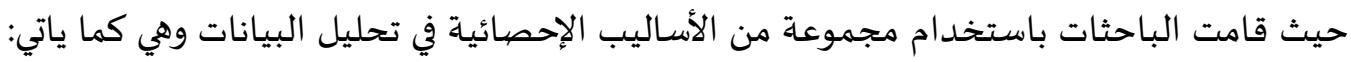

$$
\begin{aligned}
& \text { 1- المتوسطات الحسابية والانحرافات المعيارية. } \\
& \text { 2- اختبار (ت) T-test. }
\end{aligned}
$$

$$
\text { 4. عرض نتائج الدراسة وتفسيرها }
$$
هالإجابة عن السؤال الرئيس: "ما فاعلية التعلم المدمج باستخدام الويكي في تنمية مهارات التعبير الكتابي لدى

$$
\text { طلاب الصف السادس الأساسي؟ عن السؤيس }
$$

ويرتبط باه التحقق من صحة الفروض التالية:

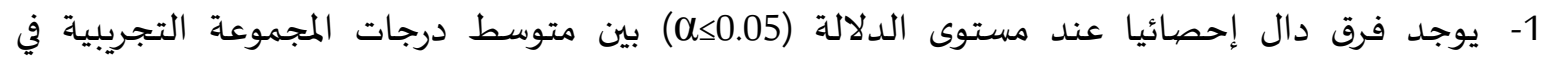

$$
\text { التطبيقين القبلي والبعدي لاختبار مهارات التعبير الكتابي لصالح الاختبار البعدي. }
$$

الفرق الإحصائي بين أداء طلاب المجموعة التجريبية في التطبيقين القبلي والبعدي لاختبار مهارات التعبير

$$
\text { الكتابي }
$$

وللكشف عن أداء طلاب المجموعة التجريبية في التطبيقين القبلي والبعدي لاختبار مهارات التعبير الكتابي طبقت الباحثة اختبار (ت) للعينات المترابطة والجدول 4 يوضح نتيجة ذلك. 
الجدول (4) الفرق الإحصائي بين أداء طلاب المجموعة التجريبية في التطبيقين القبلي والبعدي لاختبار مهارات التعبير الكتابي

\begin{tabular}{|c|c|c|c|c|c|c|}
\hline الإحصيائية الدلالة & قيمة ت & الحرية & الالنحراف & المتوسط الحسابي & العدد (ن) & المجموعة \\
\hline \multirow{2}{*}{ مستوى دالة عند 0.05} & \multirow{2}{*}{10.1} & \multirow{2}{*}{59} & 0.78 & 17,7 & 30 & التجريبية (القبلي) \\
\hline & & & 1.21 & 16 & 30 & التجريبية (البعدي) \\
\hline
\end{tabular}

حيث يتضح من الجدول وجود فروق ذات دلالة إحصائية عند مستوى الدلالة $(0,05)$ بين التطبيقين

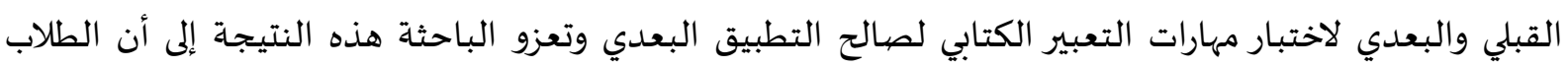

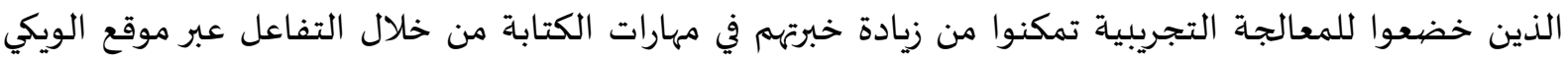

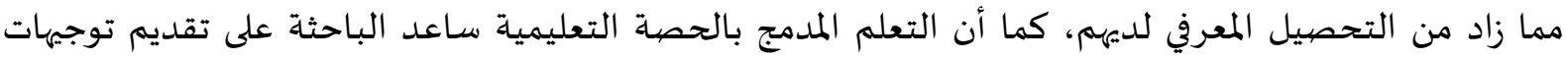

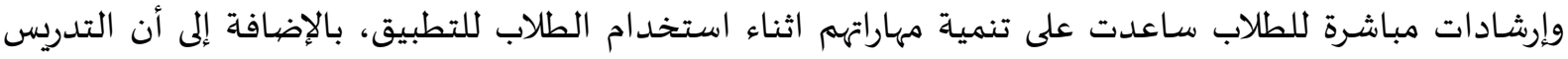

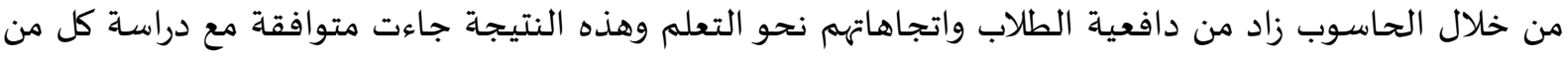
(الطريري، 2017؛الظفيري، 2017؛ سلامة وآخرون، 2018؛ عبد الغفار، 2018؛الراشدية، 2019) من حيث فاعلية

التعلم المدمج في العملية التعليمية ككل.

فحص الفرضية الثانية: يوجد فرق دال إحصائيا عند مستوى الدلالة (1<0.05) بين متوسطي درجات

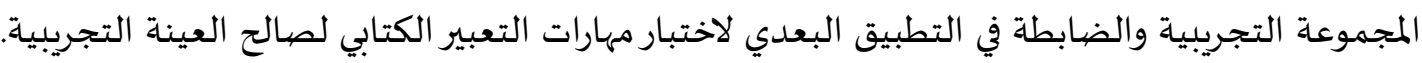

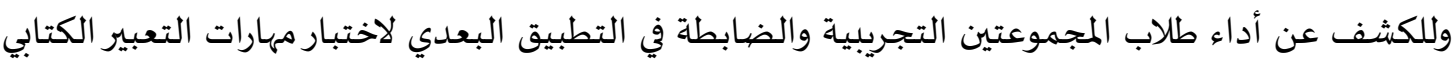

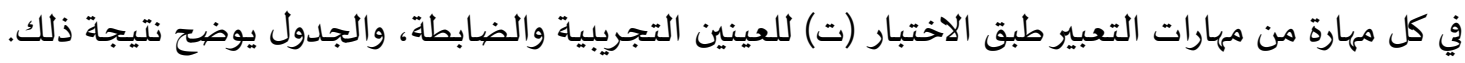

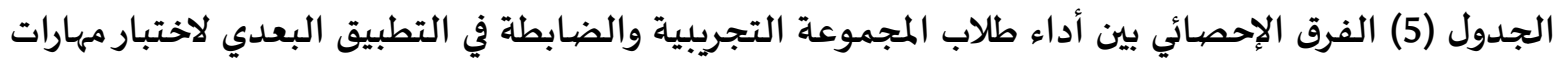

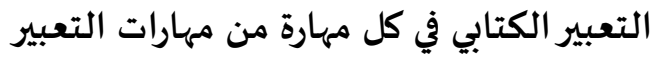

\begin{tabular}{|c|c|c|c|c|c|}
\hline مستوى الدلالة & قيمة (ت) & الانحراف المعياري & المتوسط الحسابي & المجموعة & المهارة \\
\hline \multirow{2}{*}{0.038} & \multirow{2}{*}{2.257} & 1.48 & 14.7 & التجريبية & \multirow{2}{*}{ مهارة المحتوى } \\
\hline & & 2.02 & 12.8 & الضيابطة & \\
\hline \multirow{2}{*}{0.189} & \multirow{2}{*}{1,37} & 0.66 & 7.77 & التجريبية & \multirow{2}{*}{ مهارة الشكل } \\
\hline & & 0.70 & 7.33 & الضيابطة & \\
\hline \multirow{2}{*}{0.002} & \multirow{2}{*}{3.732} & 1.16 & 12.1 & التجريبية & \multirow{2}{*}{ والأسلوب اللغة } \\
\hline & & 0.9 & 10.2 & الضيابطة & \\
\hline
\end{tabular}

حيث يتضح من الجدول أن هناك فروق دالة إحصائيا عند مستوى الدلالة (0.05) بين متوسطي درجات

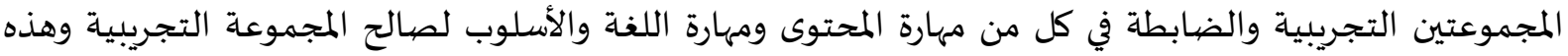

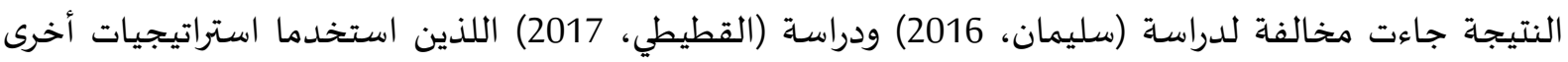

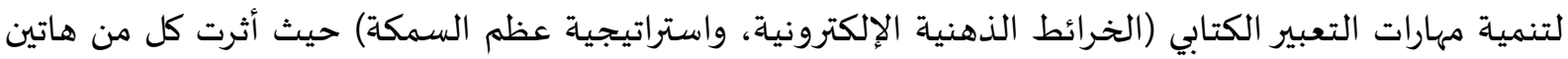

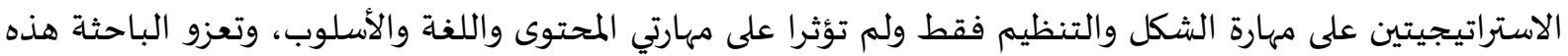
النتيجة إلى أن تطبيقات الويكي التشاركية تتيح للطلاب مشاركة أفكارهم مما يوفر للطلاب فرصية أكبر لإيضاح أفكارهم بشكل منظم ومترابط وبدون تكرار كما أن خاصية التعديل على النصوص تتيح للطلاب تصحيح الأخطاء 
الإملائية وإضافة علامات الترقيم المناسبة مما يؤثر إيجاباً في أداء الطالب لهاتين المهارتين. وهذا ما أكدته دراسة كل

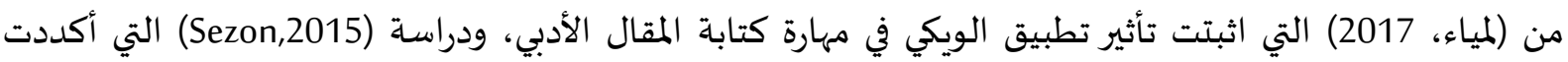

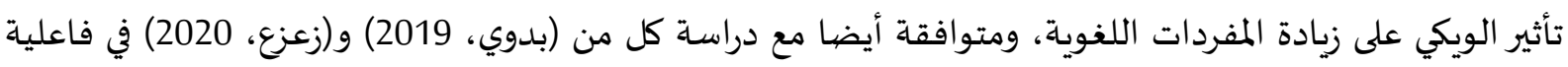

$$
\text { التتخدام الويكي التشاركي. }
$$

في ضوء النتائج التي توصلت إلها الدراسة توصي الباحثة وتقترح ما يلي:

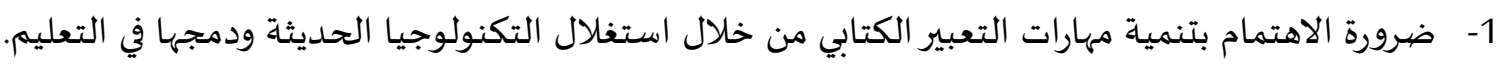

2- عقد ورش تدريبية لمعلمي اللغة العبية عن أهمية دمج التكنولوجيا في التعليم استخدام تطبيقات الويب 0.2

$$
\text { التي من شانها تنمية مهارات التعبير الكتابي. }
$$

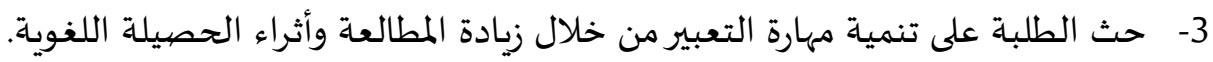

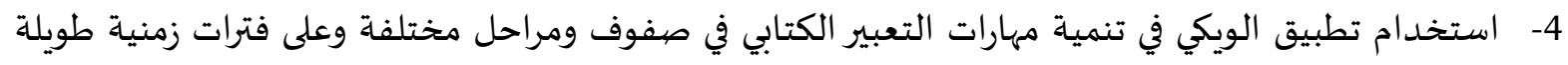
بما يقارب الفصل الدراسي. 5- استخدام تطبيق الويكي في تدريس فروع اللغة العربية الأخرى كالنحو والصرف والإملاء والبلاغة. 6- كما تقترح الباحثة إجراء المزيد من الدراسات التي تتناول الموضيوعات التالية:

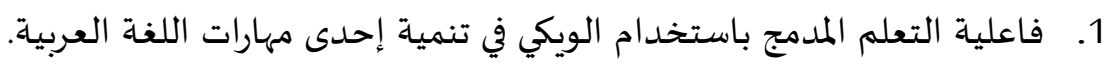
2.

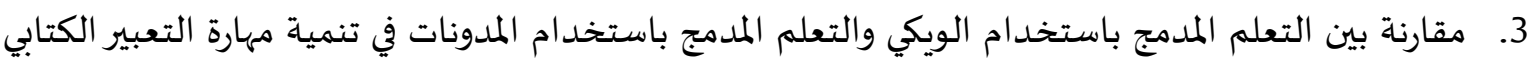

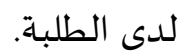

قائمة المراجع

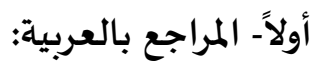

- البجة، عبد الفتاح (2016). أساليب تدريس مهارات اللغة العربية وآدابها. الإمارات العربية المتحدة: دار الكتاب

الجامعي.

- بدوي، محمد محمد عبد الهادي. (2019). فاعلية تدريس وحدة مقترحة باستخدام تقنية الويكي والخرائط الذهنية الإلكترونية ومهارات التفكير البصري لدي طلاب شعبة تكنولوجيا التعليم .مجلة كلية التربية بالمنصورة: جامعة المنصورة - كلية التربية، 105 (2)، 564-564 البوسعيدي، سالم بن سبت (2008). برنامج مقترح لعلاج الأخطاء النحوية الشائعة في التعبير الكتابي طلبة الصف الحادي عشر من التعليم العام بسلطنة عمان. (ماجستير غير منشورة)، كلية التربية، جامعة السلطان قابوس. جاد، محمد لطفي محمد (2016). برنامج مقترح لتنمية مهارات التعبير الكتابي والاتجاه نحوه لدى تلاميذ الصف

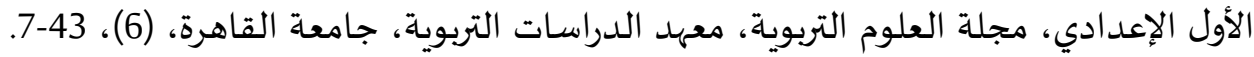

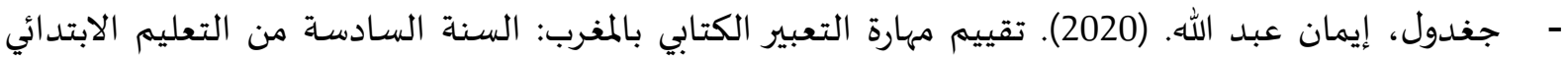
أنموذجا .مجلة العلوم التربوية والنفسية: المركز القومي للبحوث غزة، 4 (20)، 118-135. 
- الحبيشى، عبد الواحد بن رجاء الله بن عطيوى. (2020). أسباب ضعف التحصيل الدراسي لطلاب المرحلة

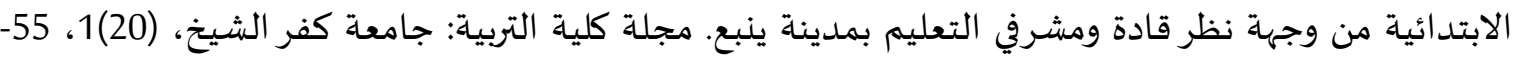

- ـ الحلفاوي، وليد سالم (2015). تكنولوجيا التعليم من التقليدية إلى الرقمية. مركز النشر العلمي، جامعة الملك عبد العزيز.

- الراشدية، موزة؛ والغتامي، سليمان بن سيف؛ والبوسعيدي، فاطمة بنت يوسف. (2019). فاعلية وحدة

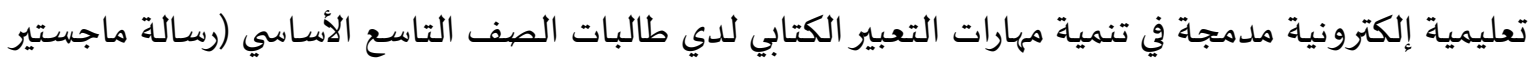
غير منشورة). جامعة السلطان قابوس، مسقط. الراميني، فواز بن فتح الله (2007). المرجع اللغوي الوافي في التعبير الإبداعي والوظيفي للتعليم العام والجامعي. العين: دار الكتاب الجامعي.

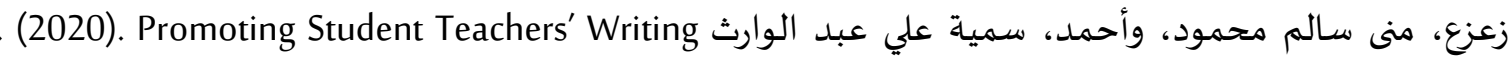
مجلة جامعة الملك عبد العزيز - الآداب Performance and Self-Regulated Learning Skills through Wikis.

والعلوم الإنسانية: جامعة الملك عبد العزيز، 28 (10).

زيتون، حسن حسين (2005). رؤية جديدة في التعليم الإلكتروني: المفهوم، القضايا، التطبيق، التقييم الرياض: الدار الصيوتية التربوية. سعيد، نهى ساهر، وآخرون. (2020). برنامج قائم على التعلم المدمج لعلاج صعوبات تعلم القراءة لدى تلاميذ

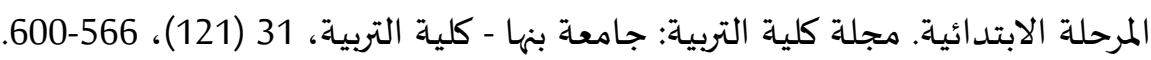

السفاسفة، عبد الرحمن إبراهيم (2011). طرائق تدريس اللغة العربية. الأردن: مكتبة الفلاح للنشروالتوزيع.

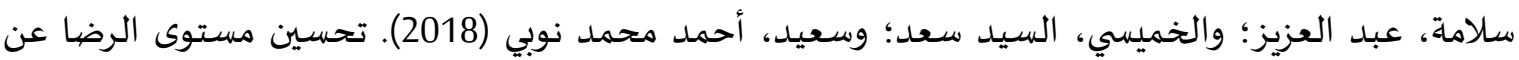
التعلم والتحصيل المعرفي باستخدام التعلم المدمج التعاوني لدى طلبة الدراسات العليا. المجلة العربية للعلوم التربوية والنفسية. 3، 41-56. سلمان، هدى محمد (2018). أثر التكنولوجيا الحديثة في تنمية مهارات طلبة الجامعة. مجلة البحوث التربوية والنفسية- العراق، 56، 196-216. سليمان، فاطمة بيت بخيت (2016). فاعلية استراتيجية الخرائط الذهنية الإلكترونية في تنمية مهارات التعبير الكتابي لدى طالبات الصف التاسع الأساسي. رسالة ماجستير غير منشورة. جامعة السلطان قابوس. - السنوني، محمد يوسف (2020). استخدام استراتيجية الفصل المقلوب وأثرها في تنمية مهارات التعبير الكتابي

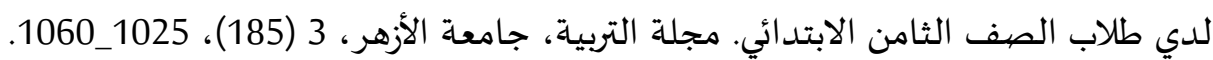

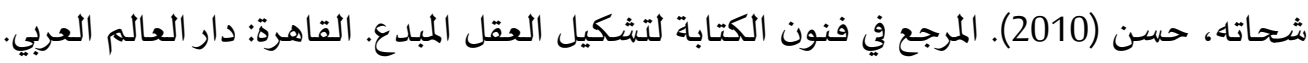
الشروف، غادة عبد القادر (1999). أثر برنامج تعليهي مقترح على التعبير الكتابي في اللغة العربية لطالبات الصف الأول الثانوي في مديرية تربية الرصيفة. (رسالة ماجستير غير منشورة). جامعة اليرموك، عمان. صومان، أحمد إبراهيم (2014). اللغه العربية وطرائق تدريسها لطلبة المرحلة الأسـاسية الأولى. الأردن: دار كنوزئه المعرفة العلمية للنشروالتوزيع. الطريري، فهد بن سعود (2016). فاعلية التعلم المدمج باستخدام الويكي سبيس في تنمية مهارات الكتابة الإملائية لدى طلاب الصف الخامس الابتدائي. الثقافة والتنمية. 17 (116)، 197- 135. 
- الظفيري، رائد عواد (2017). أثر استخدام محررات ويكي التعاونية والتنافسية في تحصيل مادة الاجتماعيات

لدى طلاب المرحلة المتوسطة بدولة الكويت. مجلة العلوم التربوية والنفسية. 1 (8). الظفيري، محمد هديني، وآخرون (2017). واقع تطبيق تلاميذ المرحلة المتوسطة بدولة الكويت لمهارات التعبير

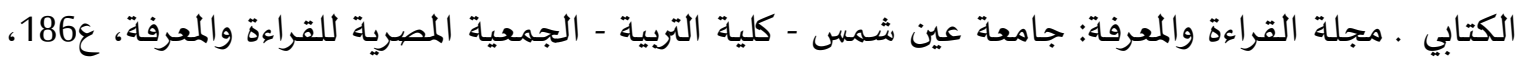

$-156.133$

عاشور، راتب؛ ومقدادي، محمد فخري (2005). المهارات القرائية والكتابية طرق تدريسها واستراتيجياتها. الأردن: دار المسيرة للنشر والتوزيع والطباعـة.

العامري، عيسى صالح (2008). مهارات التعبير الكتابي اللازمة لطلاب التعليم الأساسي ومدى تمكنهم منها. (رسالة ماجستير غير منشورة)، جامعة السلطان قابوس.

عبد العاطي، محمد الباتع (2015). توظيف تكنولوجيا الويب في التعليم. الإسكندرية: المكتبة التربوية. عبد العاطي، محمد الباتع (2016). تكنولوجيا التعليم المدمج. الإسكندرية: المكتبة التربوية.

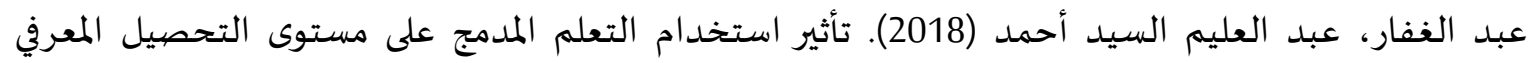
للطلبة واتجاهاتهم نحو استخدام مستحدثات تكنولوجيا التعليم. مجلة أسيوط لعلوم وفنون التربية الرياضياة.

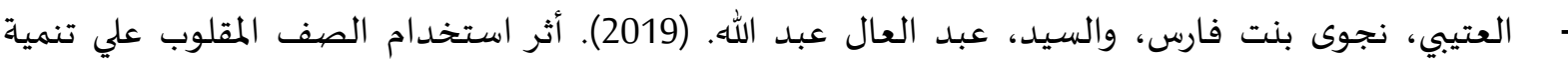
مهارات التعبير الكتابي لطالبات معهد تعليم اللغة العربية للناطقات بغيرها. مجلة كلية التربية: جامعة أسيوط كلية التربية، 35 (8)، 599-617. العجمي، سعد سالم؛ وأبو صعيليك، علي فرحان منيفي. (2019). The Effect of Using Wiki on Developing Learners' English Language Abilities عجينة، هبة (2015). مهارات التعلم أدوات التكنولوجيا العصرية. مصر: المجموعة العربية للتدريب والنشر.

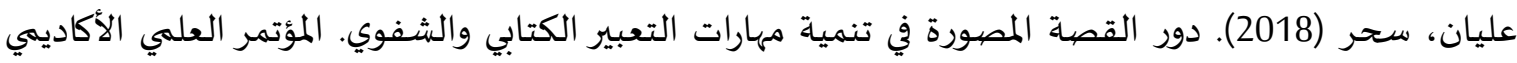
الدولي التاسع. استانبول- تركيا. الفقي، عبد اللاه إبراهيم (2011). التعلم المدمجج التصميم التعليمي- الوسائط المتعددة- التفكير الابتكاري. الأردن: دار الثقافة للنشر والتوزيع. القرني، دخيل محمد (2012). فاعلية استخدام استراتيجية التساؤل الذاتي في تنمية مهارات الكتابة الإبداعية في اللغة العربية لدى طلاب الصف الأول الثانوي. رسالة ماجستير منشورة. كلية التربية، جامعة الملك خالدالسعودية.

القطيطي، يوسف بن عبيد (2017). فاعلية التدريس باستخدام استراتيجية عظم السمكة في تنمية مهارات التعبير الكتابي لدى طلاب الصف الثامن الأساسي. (رسالة ماجستير غير منشورة)، جامعة السلطان قابوس. باسئ

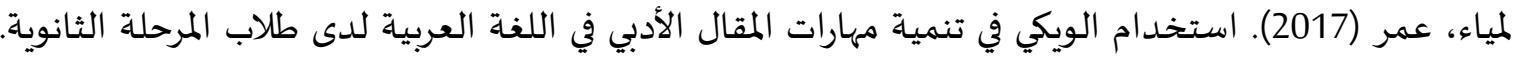
مجلة بحوث عربية في مجلات التربية النوعية. مجلة بحوث عربية في مجالات التربية النوعية.8، 179- 154. مجاور، 2000. تدريس اللغة العربية في المرحلة الثانوية أسساه وتطبيقاته التربوية، القاهرة: دار الفكر العربي.

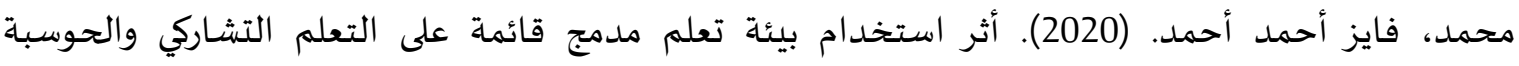
السحابية في تنمية مهارات الجداول الحسابية لدى تلاميذ المرحلة الإعدادية. دراسات في التعليم الجامعي: جامعة عين شمس - كلية التربية - مركز تطوير التعليم الجامعي، 49، 493 - 528. 


$$
\text { - مدكور، علي أحمد (2006). تدريس فنون اللغة العربية. القاهرة: دار الفكر العربي. }
$$

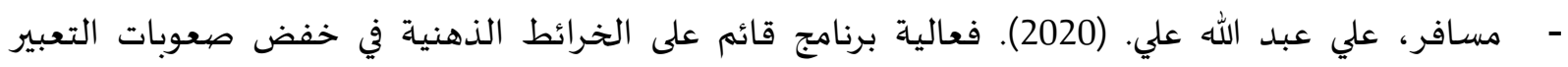

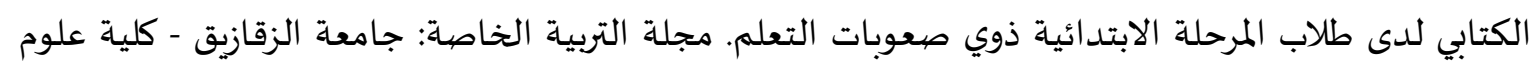
الإعاقة والتأهيل، 33، 63 - 109.

مصطفى، أحمد محمد حسين، زيدان، زينب احمد محمد، وخليفة، زينب محمد حسن. (2017). أثر استخدام التعليم المدمج في علاج صعوبات تعلم القواعد النحوية لدى تلاميذ المرحلة الابتدائية. دراسات في التهدئ التعليم الجامعي: جامعة عين شمس - كلية التربية - مركز تطوير التعليم الجامعي، 37، 583 - 590. مقلد، محمد حمود (1998). مشكلات ضعف الطلاب في التعبير. رسالة التربية، دائرة البحوث التربوية بسلطنة

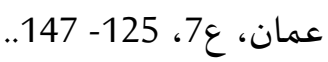
المياسي، سعيد عبد الله. (2012). الأغلاط النحوية الشائعة في التعبير الكتابي لدى طلاب الصف العاشر الأساسي بسلطنة عمان. (رسالة ماجستير منشورة)، جامعة السلطان قابوس.

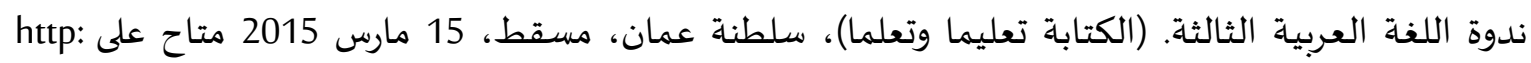
.//alwatan. com/details/51569 وزارة التربية والتعليم، (2013). دليل المعلم إلى كتاب مهاراتي في الكتابة للصف السادس الأسـاسي، مسقط، المديرية العامة للمناهج والتدريب، سلطنة ولمبنة عمان. - الوعري، هها عبد الله، والبصيص، حاتم حسين. (2019). مشكلات تدريس التعبير الكتابي الوظيفي لدى طلاب

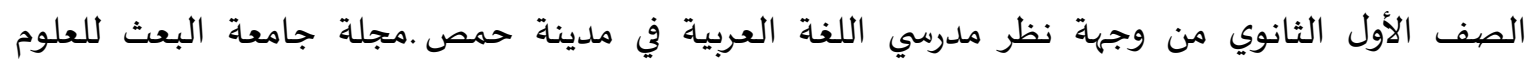

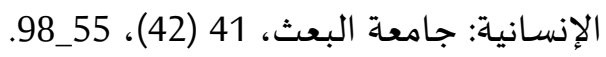

\section{ثانياً- المراجع بالإنجليزية:}

- Grote, B. (2013). Using web 0. 2 in teaching and research insights from training and user driven reseach.

- Sezen, T: 2015. The effects of blended learning on EFI students' vocabulary enhancement. Middle East Technical University,Ankara,Turkey,Social and behavioral Sciences N 199,P 641- 647,

- Thorne,K. (2003): "Blended learning: How to integrate Online and Traditional Learning" London: Kogan Page limited. , ISBN: (0749439017). 